\title{
Results of the first Wave Glider experiment in the southern Tyrrhenian Sea
}

\author{
Giuseppe Aulicino ${ }^{1,2^{*}}$ Yuri Cotroneo, ${ }^{1}$ Teodosio Lacava,${ }^{3,4}$ Giancanio Sileo, ${ }^{4}$ Giannetta Fusco, ${ }^{1,5}$ Ryan Carlon, ${ }^{6}$ \\ Valeria Satriano, ${ }^{4}$ Nicola Pergola, ${ }^{3,4}$ Valerio Tramutoli, ${ }^{3,4}$ Giorgio Budillon ${ }^{1,5}$ \\ ${ }^{1}$ Department of Sciences and Technologies, Parthenope University of Naples, Centro Direzionale isola C4, 80143 Naples, Italy; \\ ${ }^{2}$ Department of Life and Environmental Sciences, Marche Polytechnic University, Via Brecce Bianche snc, 60131 Ancona, Italy; \\ ${ }^{3}$ National Research Council, Institute of Methodologies for Environmental Analysis, C.da S. Loja, 85050 Tito Scalo (PZ), Italy; \\ ${ }^{4}$ School of Engineering, University of Basilicata, Via dell'Ateneo Lucano 10, 85100 Potenza, Italy; ${ }^{5}$ National Inter-University \\ Consortium for the Physics of Atmospheres and Hydrospheres, Piazza Mauruzi 17, 62029 Tolentino (MC), Italy; ${ }^{6}$ Liquid Robotics Inc., \\ 1329 Moffett Park Drive, Sunnyvale, CA 94063, USA \\ *Corresponding author: g.aulicino@staff.univpm.it
}

\begin{abstract}
A wave-propelled autonomous vehicle (Wave Glider) instrumented with a variety of oceanographic and meteorological sensors was launched from Gulf of Naples on the $12^{\text {th }}$ of September 2012 for a two-week mission in the Southern Tyrrhenian Sea. The main objective of the mission was a preliminary evaluation of the potential of commercial autonomous platforms to provide reliable measurements of sea surface parameters which can complement existing satellite based products moving from the local to the synoptic scale. To this aim Wave Glider measurements were compared to equivalent, or near-equivalent, satellite products achieved from MODIS (Moderate Resolution Imaging Spectroradiometer) sensors onboard the EOS (Earth Observing System) satellite platforms and from AVISO (Archiving Validation and Interpretation of Satellite Oceanographic Data). Level-3 near real time and Level-4 reprocessed sea surface foundation temperature products provided by the CMEMS (Copernicus Marine Environment Monitoring Service) were also included in this study as well as high resolution model output supplied by NEMO (Nucleus for European Modelling of the Ocean). The Wave Glider was equipped with sensors to measure temperature, salinity, currents, as well as Colored Dissolved Organic Matter (CDOM), turbidity and refined fuels fluorescence. The achieved results confirmed the emerging value of Wave Gliders in the framework of multiplatform monitoring systems of the ocean surface parameters. In particular, they showed that Wave Glider measurements captured the southern Tyrrhenian Sea major surface oceanographic features, including the coast to open sea haline gradient and the presence of a cyclone-anticyclone system in the southeastern subregion. The Wave Glider also had the capability to monitor upper ocean currents at finer spatial and temporal scales than satellite altimetric observations and model outputs. Nonetheless, results stressed the existence of several limits in the combined use of satellite and Wave Glider observations and the necessity of further analyses concerning the monitoring of the ocean optical properties. In fact, Wave Glider and satellite-based products agree in terms of sea surface temperature and currents patterns, while bio-optical properties turned out to be less well correlated. No significant traces of refined fuels have been detected along the Wave Glider track.
\end{abstract}

Key words: Wave Glider; southern Tyrrhenian Sea; multiplatform monitoring; remote sensing; sea surface temperature; surface layer circulation; altimetry.

Received: December 2015. Accepted: March 2016.

\section{INTRODUCTION}

The Tyrrhenian Sea (TYS hereafter) is an area of considerable oceanographic interest in the Mediterranean region, being the deepest and the most isolated basin of the western Mediterranean Sea (Fig. 1). Three main openings connect this basin to the western (Sardinia and Corsica Channels) and eastern (Sicily Strait) Mediterranean Sea. In spite of its marginal position, several studies of TYS hydrology and dynamics assessed its direct influence on the entire Mediterranean Sea thermohaline circulation (Krivosheya 1983; Hopkins 1988; Astraldi and Gasparini 1994) which plays a fundamental role by supplying the global ocean with dense water whose properties have shown intense variability in the recent decades (Millot et al., 2006; Fusco et al., 2008).
Several water masses occupy this basin from surface to deep layers. An important vein of modified surface waters of Atlantic origin (AW) typically lies in the upper 100-200 m of the water column (Millot, 1987; Astraldi et al., 1996; Millot, 1999; Fusco et al., 2003; Budillon et al., 2009). These waters, identified by a subsurface salinity minimum $(S<37.4)$, enter the basin mainly along the southern boundary, leaving the Algerian basin and flowing along the northern coast of Sicily (Astraldi et al., 2002; Poulain and Zambianchi, 2007). At subsurface levels the salty $(\mathrm{S}>38.5)$ Levantine Intermediate Waters (LIW) coming from the eastern Mediterranean Sea reach the TYS through the Sicily Strait and successively get transformed and mixed (Millot, 1987; Hopkins, 1988; Astraldi et al., 1996). The deepest layer is filled by the Western Mediterranean Deep Water (WMDW), characterized by lower po- 
tential temperature $\left(\theta<13.0^{\circ} \mathrm{C}\right)$ and salinity $(\mathrm{S}<38.5)$, entering the TYS through the deep part of the Sardinia-Sicily section (Millot 1999). The relatively weak dynamics within the deep layer and the presence of gyre structures (Astraldi and Gasparini, 1994) result in mixing processes between LIW and WMDW, with the consequent formation of a peculiar water mass (named Tyrrhenian Deep Water) positioned below $1000 \mathrm{~m}$ depth (Hopkins, 1988; Millot, 1999; Budillon et al., 2009).

The general TYS circulation is cyclonic along the boundaries, according to the general Mediterranean circulation, but several closed structures can be detected both in the northern and in the southern regions of the basin (Fig. 1). In the surface layer, these structures are mainly driven by wind and its spatial variability, especially in the northern and central TYS. Some quasi-permanent features characterize the western part of the basin: a wide cyclonic area frequently observed southeast of Sardinia and a cyclonic-anticyclonic system just east of the Bonifacio Strait (Astraldi and Gasparini, 1994; Millot, 1999; Vignudelli et al., 2003; Budillon et al., 2009). The southern part of the basin is more influenced by the recirculation processes occurring at its meridional openings, as confirmed by the analyses of drifter trajectories presented by Rinaldi et al. (2010). These processes are mainly driven by steric level gradients existing between TYS and neighboring basins. Classical studies (Astraldi and Gasparini, 1994; Marullo et al., 1994; Fusco et al., 2003) suggest that the summer circulation is completely different from that of winter, with transition periods occurring in May-June and SeptemberOctober. In particular, during winter a basin-scale cyclonic cell drives surface waters (AW) from the south up to the Ligurian Sea (Fig. 1a). During summer, indeed, the TYS basin is isolated from the rest of the Mediterranean Sea by intense thermohaline fronts (Fig. 1b). The resulting circulation has a more fragmentary pattern: the cyclonic centers intensify, the AW flow weakens and the presence of additional eddies in the eastern TYS is favored.

Over the years, the presence of gyre structures in both seasons has been extensively described using in situ data (Krivosheya and Ovchinnikov, 1973) as well as satellite sea surface temperature (SST) images (Marullo et al., 1994) and altimetry data (Vignudelli et al., 2003). All these studies reported the presence of quasi-permanent and intermittent cold and warm structures even if only few detailed works exist about their formation and evolution a

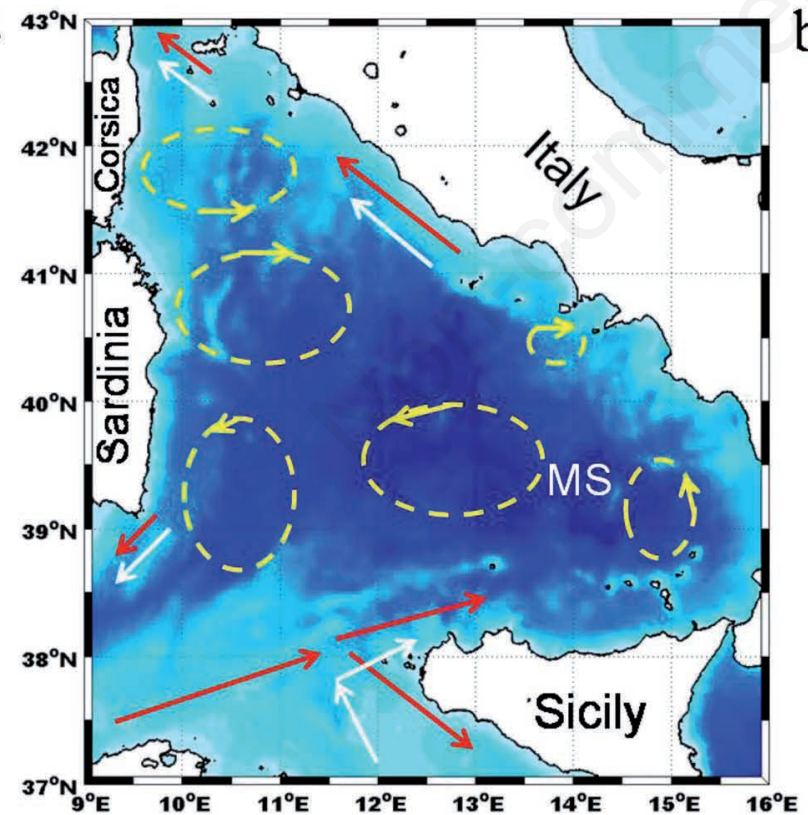

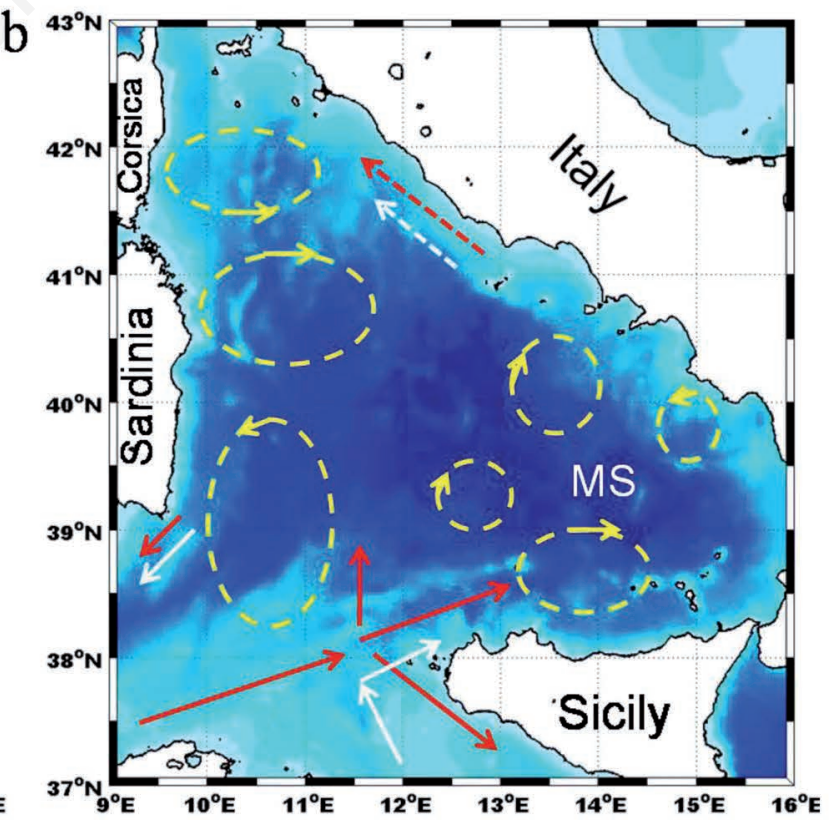

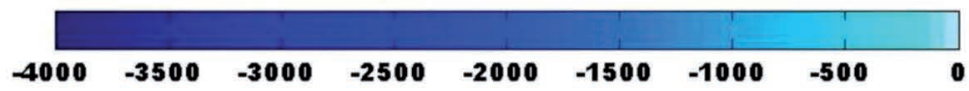

Fig. 1. Southern TYS general features for winter (a) and summer (b) periods. TYS main openings are the Corsica Channel, the Sardinia Channel and the Sicily Strait. Shading indicates bathymetry and arrows indicate the main patterns of surface (AW, red) and intermediate (LIW, grey) waters. Dashed ovals schematize the quasi-permanent features of the TYS circulation: the cyclonic-anticyclonic system in front of the Bonifacio Strait and the cyclonic circulation between Sardinia and Sicily. The location of the Marsili Seamount (MS) is also reported on the map. 
(Artale et al., 1994; Pierini and Simioli, 1998). In recent years, Rio et al. (2007) showed the presence of a basin wide cyclonic circulation and some large recirculation cells from altimeter, in situ and model data, while Iacono et al. (2013) identified nine vortices in the eastern TYS, that appear to be robust features of the circulation, on the basis of Sea Level Anomaly (SLA) and Absolute Dynamic Topography (ADT) maps. Also, the drifter data analyzed by Rinaldi et al. (2010) gave a significant contribution suggesting the presence of a strong and recurrent anticyclonic circulation offshore of the Gulf of Naples, the prevalence of an anticyclonic circulation near the northern coast of Sicily and the persistence of a cyclonic gyre that extends until $40^{\circ} \mathrm{N}$ in the southeastern TYS.

In spite of its great importance, the role played by the mean flow and the high variability of the TYS topography, including the presence of several seamounts, is still largely unknown. Previous studies in the central TYS (Budillon et al., 2009) and pre-existent laboratory and numerical modelling simulations (Verron and Le Prevost, 1985; Chapman and Haidvogel, 1992) indicate this effect as a possible cause of the presence and persistence of eddies in the region. In this context, the possibility to complement wide-scale satellite observations with in-situ measurements collected at higher space-time density, can be of paramount importance in order to better investigate and model processes developing in the TYS at very different space-time scales.

The main purpose of this work is to present the results of the first Wave Glider (hereafter WG) experiment in the southern part of the TYS, a mission carried out between the $12^{\text {th }}$ and the $26^{\text {th }}$ September 2012 in the framework of the RITMARE (La Ricerca ITaliana per il MARE - The Italian research at sea) project. This experiment, based on the use of a SV2 Liquid Robotics WG, allowed us to perform a remotely-guided surface monitoring of the TYS region embedded between the Gulf of Naples and the Marsili Seamount (Fig. 1). The WG campaign was performed during the central weeks of September in order to partially fill the lack of in situ information concerning the transition period between summer and winter conditions.

The advantages of using an unmanned maritime vehicle (UMV) like the WG are many. Although they do not completely substitute oceanographic ship cruises, autonomous ocean observing systems (e.g., UMVs, AUVs, floats, etc.) collect, via electronic or optical sensors, a wide range of in situ data, stored or transmitted directly to shore, providing high resolution insights of oceanographic properties and dynamics from basin-scale to submesoscale (Cotroneo et al., 2015) with lower cost compared with the use of research vessels (Villareal and Wilson, 2014). In particular, WGs allow fine scale spatial and temporal continuous measurements, easy and almost immediate deployment at short notice, as well as near real time track changes to make observations of unexpected and interesting phenomena at sea. Also, WG data can help to evaluate satellite product accuracy, can be used to complement other in situ information or can be used to calibrate and validate ocean models. At present, the most crucial limitation of WGs is the lack of depth profiles and of synoptic coverage over long distances due to limited speed (Goebel et al., 2014).

In this study, data collected by the WG were coupled to a substantial satellite dataset in order to assess the functionality of the WG over the southern TYS and assess the capability of its in situ observations to complement, at a refined spatial scale, existing satellite products. Moreover, ocean current data collected by the WG have been compared with surface circulation output derived from an hydrodynamic model for the Mediterranean Sea. The paper is organized as follows. In section 2, WG settings and data are described, as well as the large set of satellite and model products included in this work. In section 3, results inferred from the WG dataset and the satellite/model derived information are analyzed. The TYS features detected by both platforms are discussed considering their combination and inter-comparison. Results are summarized in section 4 where some directions of future work are also indicated.

\section{METHODS}

\section{Wave Glider data}

The WG (Fig. 2) is an unmanned maritime vehicle (UMV) unique in its ability to harness ocean wave energy for platform propulsion. This autonomous sampling system uses a series of wings located on a sub-body at 5.8 meters below the surface to propel the vehicle forward using the vertical motion induced by wave motion, independently of wave direction. The wave energy propulsion system is purely mechanical. As waves pass by on the surface, the submerged glider acts as a tug, pulling the surface float along a predetermined course (Wilcox et al., 2009). There is substantial power available in ocean waves so that WG harnesses part of this power to maintain an average forward speed from 0.4 to 1.5 knots, depending on sea state (Hine et al., 2009). This energy can be used for locomotion to reach any point of interest as well as for station keeping once that position is reached.

The vehicle consists of a low-profile surface float equipped with solar panels that provide power for the sampling systems, navigation systems (GPS satellite transmissions) and satellite telemetry links (Iridium ${ }^{\circledR}$ Satellite). The subsurface board is connected to the surface payload by a tether (umbilical). Real time communication with the shore-based operator allows monitoring of platform location and data gathering. 
The Liquid Robotics Inc. (LRI) WG-SV2 involved in this study supported four sampling systems: an Airmar PB200 weather station collecting air temperature, barometric pressure, wind speed, wind gust speed, and wind direction at one meter height; a Turner Designs C3 submersible fluorometer equipped to measure Colored Dissolved Organic Matter (CDOM), refined fuels concentration and turbidity; a pumped Seabird Electronics Glider Payload Conductivity, Temperature, Depth (CTD) sensor; an Acoustic Doppler Current Profiler (ADCP) WorkHorse Monitor by Teledyne/RD Instruments operating at $300 \mathrm{kHz}$ (Fig. 2). Tab. 1 gives an overview of the main WG characteristics and capabilities. Additional information is available from the LRI webpage (http://liquid-robotics.com).

The weather station is based on ultrasonic technology with wind corrections for pitch and motion based on a three-axis compass, yaw-rate gyro and GPS information. The wind sensor anemometer measures $0-360^{\circ}$ wind velocity between $-360^{\circ}$ wind velocity between 0 and $40 \mathrm{~m}$ $\mathrm{s}^{-1}$ with a resolution of $0.1^{\circ}$ and $0.1 \mathrm{~m} \mathrm{~s}^{-1}$ and an accuracy of $2-8^{\circ}$ and $0.5-2.5 \mathrm{~m} \mathrm{~s}^{-1}$ (the worst in occurrence of wet conditions). The temperature sensor ranges between $25^{\circ} \mathrm{C}$ and $55^{\circ} \mathrm{C}$ (with a resolution of $0.1^{\circ} \mathrm{C}$ and an accuracy of $\pm 1.0^{\circ} \mathrm{C}$ ) while the atmospheric pressure sensor ranges between 850 and 1150 mbar (with a resolution of 0.1 mbar and an accuracy of \pm 2 mbar).

CDOM, refined fuels and turbidity measured by the
C3 system are reported in Relative Fluorescence Units (RFU). A conversion of RFU values into practical units is possible according to the $\mathrm{C} 3$ pre- and post-deployment standard calibrations of the fluorometer sensor provided by LRI. In particular, the C3 system has been calibrated using naphthalene for the refined fuels channel, quinine sulfate for the CDOM and 3000 Nephelometric Turbidity Units (NTU) for the turbidity. Nonetheless, it is important to be aware that the used reagents could be not representative of what exact fluorescing species are in the water column where the instrument is actually placed. Moreover fluorometer sensors, of the type similar to the one used on WGs, demonstrate drift over time and require frequent calibration for a proper conversion from RFU to practical units (Goebel et al., 2014). Unfortunately, during this deployment WG optical observations have not been calibrated against measurements of chlorophyll-a concentration chemically extracted from co-located water samples in order to overpass these issues. Consequently, in this work RFU values have been used for the three channels (i.e., CDOM, refined fuels and turbidity) in place of part per billion (ppb) of standard units. This avoids any possible misinterpretation of observed data during RFU to concentration conversion.

The Seabird CTD acquires with an accuracy of 0.003 $\mathrm{mS} \mathrm{cm}{ }^{-1}$ for conductivity, $0.002^{\circ} \mathrm{C}$ for sea temperature and $0.1 \mathrm{dbar}$ for pressure. The sampling interval for the

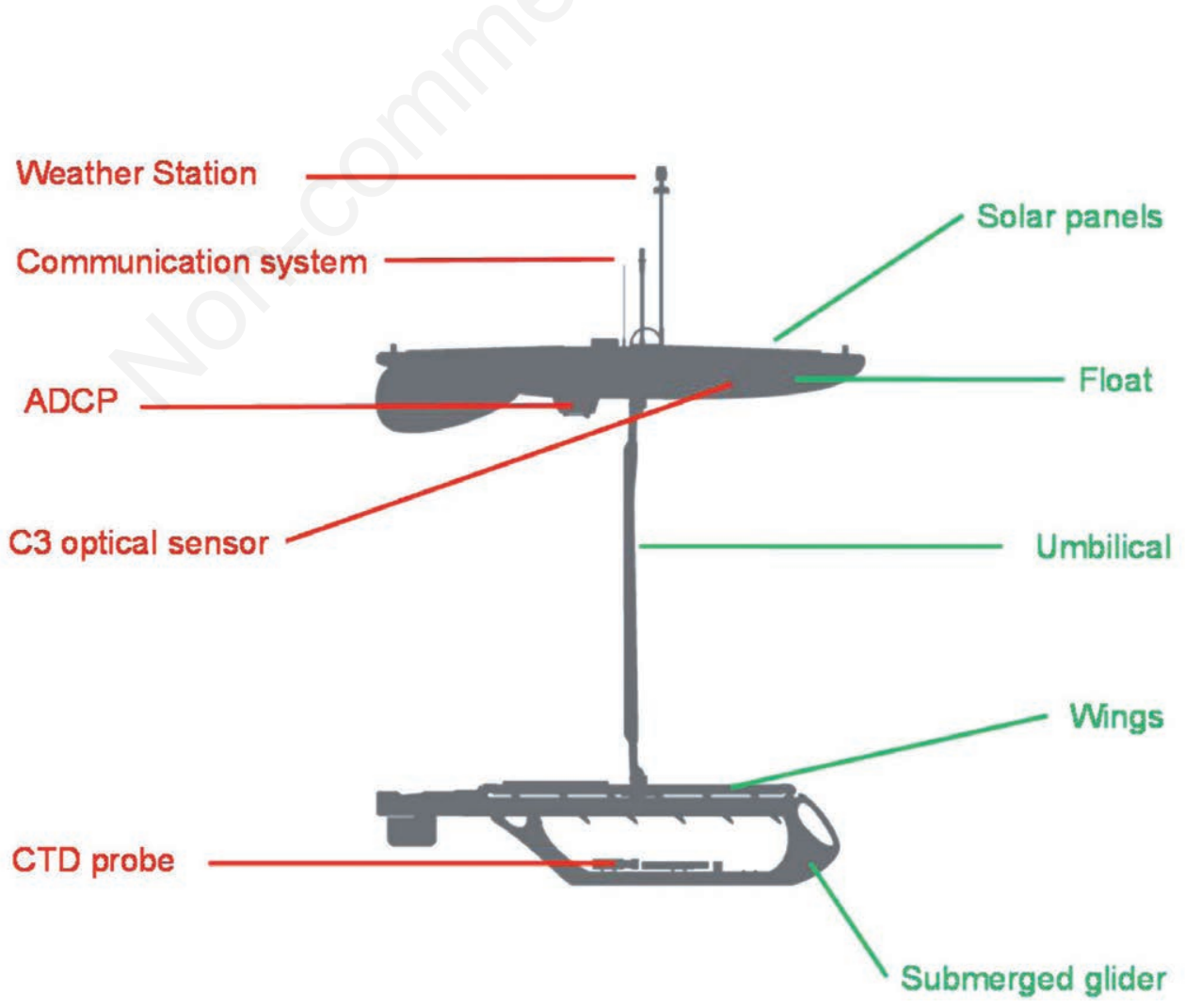

Fig. 2. Wave Glider main instrumentations (red) and components (green). 
weather data was 10 min, while for the CTD and the $\mathrm{C} 3$ sensors it was 60 and $120 \mathrm{~s}$ respectively.

The ADCP system has a compass resolution of $0.01^{\circ}$ (accuracy of $\pm 2^{\circ}$ ) and was set for investigating several depths (at 6, 10, 16, 26, 46 and 66 meters) with a current velocity resolution of $0.1 \mathrm{~cm} \mathrm{~s}^{-1}$ (accuracy of $0.5 \%$ of measured velocity $\pm 0.5 \mathrm{~cm} \mathrm{~s}^{-1}$ ). These averaged depths (also called bins) are the effective centers of cell size of 4 meters each. For conversion of bins to actual depth values, a draught of $0.25 \mathrm{~m}$ was applied for the distance of the ADCP below the water surface. Please note that the observations at 6 meters depth have not been included in this study because of contamination of the data in the upper water layers by the WG driving mechanism (placed at 5.8 meters depth). Pulses were averaged into ensembles at a time interval of 120 seconds and corrected for the motion of the vehicle. The ensemble averaging reduces random errors and bias as suggested by Fitzpatrick et al. (2014) and previously detailed in Teledyne (2011). The motion correction was done by estimating the velocity of the vehicle during each ensemble, using the GPS coordinates recorded at the beginning and end of each ensemble period. The calculated WG velocity is then subtracted from the ensemble to provide an estimate of the actual current velocity. According to Beatman et al. (2013), additional post-processing operations excluded data while the WG was turning, that means while the vehicle has a heading change of more than $30^{\circ}$ between two 120 seconds averaged samples.

All the data collected by WG were stored onboard and relayed via satellite link to LRI. In this study, subsets of data from the CTD sensors, the $\mathrm{C} 3$ sensors, the ADCP system and the weather instrumentation are examined. Data referring to periods when the WG was out of the water, identified through negative CTD pressure values (indicative of depth), were eliminated. Before being processed, all the measurements contained in these subsets were averaged in ten minutes ensembles (Fitzpatrick et al., 2014). A comparison with the full resolution datasets was performed to avoid any lack of information.

\section{Satellite data}

\section{Satellite sea surface temperature and ocean color data}

The WG data were compared with Sea Surface Temperature (SST), chlorophyll concentration and Kd490 (the diffuse attenuation coefficient for downwelling irradiance at 490-nm, which is a good proxy for turbidity) products from MODIS. In detail we used products at different processing levels depending on the specific investigation we carried out. Eight days composite MODIS (Moderate Resolution Imaging Spectroradiometer) AQUA Level 3 SST maps at $4 \mathrm{~km}$ of spatial resolution were used to describe the quasi-synoptic conditions of the enquired area during the WG mission. Daily Level 2 Ocean Color (OC) and SST products at $1 \mathrm{~km}$ resolution, generated after each Terra and Aqua MODIS acquisition, were used for an almost punctual match-up with the WG data. MODIS OC and SST products available for the WG mission were downloaded from the NASA Ocean Color portal (http://oceancolor.gsfc.nasa.gov). Several OC geophysical variables were analyzed: chlorophyll concentration (chlor-a) derived through OCI algorithm (Hu et al., 2012), chlorophyll concentration (chlor-ocx) derived through OC3 algorithm (O'Reilly et al., 2000) and diffuse attenuation coefficient of downwelling radiative flux (Kd_490). Also the information about CDOM is provided by NASA Ocean Color portal, but in terms of a dimensionless index representing its excess (or deficit) with respect to its average value, chlorophyll-a dependent, in a specific area

Tab. 1. Wave Glider main characteristics and capabilities.

\begin{tabular}{|c|c|}
\hline $\begin{array}{l}\text { Physical carachteristics } \\
\text { Configuration }\end{array}$ & Submerged glider connected to a surface float by a tether \\
\hline Dimensions & $\begin{array}{l}\text { Float: } 2.1 \mathrm{~m} \times 0.6 \mathrm{~m} \\
\text { Glider: } 1.9 \mathrm{~m} \times 0.4 \mathrm{~m} \\
\text { Wings: } 1.1 \mathrm{~m} \text { total width }\end{array}$ \\
\hline Weight and buoyancy & About $75 \mathrm{Kg}, 150 \mathrm{~kg}$ displacement \\
\hline Endurance & Up to 1 year \\
\hline \multicolumn{2}{|c|}{ Capabilities and functionality } \\
\hline Propulsion & Wave energy \\
\hline Speed & $>0.5 \mathrm{kt}$ in Sea state $1 ;>1.5 \mathrm{kt}$ in Sea state 3 \\
\hline Battery & $86 \mathrm{~W}$ solar panel charging a $665 \mathrm{Wh}$ Li-on battery pack \\
\hline Payload power & About $10 \mathrm{~W}$ continuous \\
\hline Comunication systems & Iridium Satellite modem; RF Modem \\
\hline Navigation systems & 12 channel, WAAS enabled GPS; Compass \\
\hline Emergency devices & Light and RF beacon \\
\hline
\end{tabular}


(Morel and Gentili 2009). For this reason, the CDOM index is not directly comparable to the collected WG data and was not further analyzed in this paper. Nonetheless, as discussed in section 3.2, WG CDOM measurements were compared with OC chlor-a and -ocx data in order to evaluate the contribution of CDOM dynamics to the MODIS chlorophyll observations.

Daily MODIS images were used for the match-up with the WG data. Such an operation was made by averaging all glider data within $\mathrm{a} \pm 2 \mathrm{~h}$ temporal window in correspondence of usable MODIS data. In Tab. 2 the number of images available for the test area is reported. The Earth Observing System satellites constellation provided about two images per day. Concerning SST, both diurnal and night-time data have been used in this paper, allowing a more robust comparison from a statistical point of view. Moreover, several sea surface foundation temperature (SSTfnd) products, which includes diurnal variation correction, were compared with WG SST observations. In particular, Level-3 near real time and Level-4 reprocessed products provided by the CMEMS (Copernicus Marine Environment Monitoring Service) were included in this study. Daily Level-3 adjusted SSTfnd ultra high resolution products are operationally produced and distributed on a $0.01^{\circ}$ $\mathrm{X} 0.01^{\circ}$ grid over the Mediterranean Sea by the Istituto di Scienze dell Atmosfera e del Clima - Gruppo di Oceanografia da Satellite (CNR ISAC-GOS). This dataset is made of single daily super-collated images which are obtained by merging different Level-3 images retrieved from several sensors. Differences among the sensors (number of bands, spectral resolution, scanning/viewing geometry, etc.) and/or discrepancies due to the different algorithms applied to retrieve brightness temperature are adjusted through the use of best measure algorithms which keeps into account the continuity of the data present in the single image for each pixel (Buongiorno Nardelli et al., 2013). High resolution Level-4 reprocessed daily gap-free maps of SSTfnd are delivered by CNR ISAC-GOS on a regular $0.0417^{\circ} \mathrm{X}$ $0.0417^{\circ}$ grid over the Mediterranean Sea. This product is based on the optimal interpolation of AVHRR Pathfinder (version 5.2) dataset (http://pathfinder.nodc.noaa.gov)

Tab. 2. Number of MODIS products available for the investigated area during the WG mission (i.e., 12-26 September 2012).

\begin{tabular}{lcc} 
MODIS SST_LAC_L2 available products & & \\
& Day & Night \\
\hline Aqua & 21 & 21 \\
Terra & 20 & 26 \\
\hline MODIS OC_LAC_L2 available products & & \\
Aqua & 21 & \\
Terra & 19 \\
\hline
\end{tabular}

using an adapted algorithm which chooses the proper covariance models for each specific area (Buongiorno Nardelli et al., 2013). Datasets, products specifications and quality information are available at http://marine.copernicus.eu. Matlab, Ocean Data View, SEADAS and Quantum GIS were used to analyze and visualize the processed OC, SST and SSTfnd data.

\section{Satellite sea level data}

High-quality altimeter data over the TYS area have been used to investigate specific aspects of the surface circulation during the WG mission period. Satellite altimetry data were provided by AVISO (Archiving Validation and Interpretation of Satellite Oceanographic data, http://www.aviso.altimetry.fr/en/data.html). In particular, 'all sat merged' multi-mission maps of SLA and Geostrophic Velocity Anomalies, as well as 'all sat merged' maps of ADT and absolute geostrophic velocities were used to describe the basin scale circulation of the study area. The entire dataset is available on a $1 / 8^{\circ} \mathrm{X} 1 / 8^{\circ}$ regular Cartesian grid and results from the merging process of all missions available at a given time. Consequently, this series is better in quality but not homogeneous over the time period. Gridded sea surface heights (SSH) and corresponding geostrophic velocity anomalies are computed with respect to a twenty-year mean (1993-2012). The twenty year reference period is also used for gridded SSH above geoid and corresponding absolute geostrophic velocities. ADT has been computed as the sum of SLA and mean dynamic topography (SMDT-MED-2014). Anyway, it is important to remark that the altimeter data do not provide information on the circulation at the sea surface, which is dominated by high frequency wind forcing, but the signal is an integrated one which reflects the motion of the main pycnocline (Wunsch, 1997), i.e. the region of transition between the AW and the LIW. This region is quite shallow in the TYS (100-200 meters maximum depth) so that its motion is expected to dominate the geostrophic dynamics of the surface layer. The horizontal resolution of SLA maps is insufficient to identify most of eddies with sizes smaller than thirty kilometers, even if Pascual et al. (2007) indicates that merging data from at least three altimeter missions is sufficient for a correct monitoring of the mesoscale circulation of the Mediterranean Sea and that four may resolve circulation features with sizes significantly smaller than $1 / 8^{\circ}$. We can therefore expect that eddies with a size of about $100 \mathrm{~km}$, or slightly smaller, could be sufficiently resolved over most of the dataset (Iacono et al., 2013).

\section{Modeled horizontal velocity data}

High resolution physical reanalysis over the TYS provided by INGV (Istituto Nazionale di Geofisica e Vulcanologia) were used to enrich the study of the surface 
circulation during the WG mission period. Daily mean modeled horizontal velocity (meridional and zonal component) data, derived from version 3.2 of the Ocean General Circulation Model code supplied by Nucleus for European Modelling of the Ocean-Ocean Parallelise (hereafter NEMO), were included in this study. The hydrodynamic model has a horizontal grid resolution of $0.0625^{\circ} \mathrm{X} 0.0625^{\circ}$ (about 6-7 km) and 72 unevenly spaced vertical levels (Oddo et al., 2009). The NEMO model is initialized at the $1^{\text {st }}$ January 1985 with two years of spin-up. It is located in the Mediterranean Basin but also extend into the Atlantic in order to better resolve the exchanges with the Atlantic Ocean at the Strait of Gibraltar. Ocean model data output from a single consistent dedicated ocean dynamic model forced by consistent reprocessed historical observational data (surface winds, heat, and freshwater), assimilating consistent reprocessed historical observational data (in situ temperature and salinity, satellite altimetry). The model is forced by momentum, water and heat fluxes interactively computed by bulk formulae using the 6 -h, $0.75^{\circ}$ horizontal-resolution ERA-Interim reanalysis fields from the ECMWF (European Centre for Medium-Range Weather Forecasts). The water balance is computed as Evaporation minus Precipitation and Runoff (considering ERA-Interim precipitations at $6-\mathrm{h}, 0.75^{\circ}$ horizontal-resolution, evaporation derived from the latent heat flux and monthly mean runoff provided by the Climate Prediction Centre Merged Analysis of Precipitation and the Global Runoff Data Centre datasets. In this study, WG ADCP observations have been compared to co-located (in space and time) NEMO daily mean horizontal velocities in the 11 levels between 11.55 and $66.45 \mathrm{~m}$ depth.

\section{RESULTS AND DISCUSSION}

The WG cruise lasted 14 days covering a great part of the southern TYS (Fig. 3a). According to the structure of other in situ datasets and basing on up to date knowledge of basin dynamics, the collected data should be split into different subsets to guarantee their synoptic representation. The entire September 2012 WG dataset has been divided into three main legs: i) the first leg (L1 - red line in Fig. 3a) from the $12^{\text {th }}$ to the $15^{\text {th }}$ includes the southward cruise from the Gulf of Naples to the $38.8^{\circ} \mathrm{N}$; ii) the second (L2 - green line in Fig. 3a) from the $15^{\text {th }}$ to the $22^{\text {nd }}$ concerns the monitoring of the Marsili Seamount sub-region; iii) the third (L3 - blue line in Fig. 3 a) from the $22^{\text {nd }}$ to the $26^{\text {th }}$ corresponds to the northward cruise back to the Gulf of Naples. This fragmentation of the data also reflects the effective cruise sampling plan, with two long meridional transects across the Southern TYS and one intense sampling area located over the Marsili Seamount.

The analyses of collected data includes in situ obser- vations that belong to three main groups: i) seawater physical properties data $(\mathrm{T} / \mathrm{S})$; ii) currents intensity and direction; iii) turbidity, CDOM and refined fuel concentrations.

\section{Sea water physical properties and currents}

The potential temperature $(\theta)$ versus salinity (S) diagram (Fig. 3b) summarizes the hydrological characteristics of the TYS surface layer observed by the WG during the overall mission (at a mean depth of about $5.8 \mathrm{~m}$ ). This near-surface layer is characterized by the presence of a relatively warm and salty water showing $\theta$ values greater than $23^{\circ} \mathrm{C}$ (with a maximum of $25.8^{\circ} \mathrm{C}$ ) and salinities spanning between 37.9 and 38.4. This surface water mass is strongly influenced by the summer weather conditions and is known to occupy the upper mixed layer on top of the underlying fresher and colder AW core.

The variation in the water masses properties during the two weeks survey, shows a decrease in temperature along the WG cruise. In fact, coastal waters near the Gulf of Naples observed at the beginning of the cruise (A subset in Fig. 3b) show higher potential temperatures than waters occupying the same position on the $26^{\text {th }}$ September (D subset), while their $\mathrm{S}$ values remain almost unchanged. A similar temperature gradient $\left(\approx 2^{\circ} \mathrm{C}\right)$ is evident for $\mathrm{B}$ and $\mathrm{C}$ data subsets, corresponding to the first (southward) and last (northward) transects respectively. Again, their S values are almost unchanged. On the other hand, changes in salinity are evident moving from subset $\mathrm{A}$ to $\mathrm{B}$ and from $\mathrm{C}$ to $\mathrm{D}$, reflecting a typical coastal to open-sea haline gradient. The observed decrease in water temperature is in agreement with the expected variation due to the changing weather conditions during the 15 days cruise over the large study area and is consistent with the frontal structure described later in this section.

However, using information retrieved from satellite datasets, it is possible to observe that during the entire mission, the general pattern of SST and SSH remains almost unchanged suggesting a possible use of the WG data as a whole quasi-synoptic dataset. SST maps obtained by MODIS AQUA level-3 composites on 8 days for the periods from the $13^{\text {th }}$ to the $28^{\text {th }}$ of September 2012, show the evolution of a zonal SST gradient that lasts for the entire WG cruise (Fig. 4). Even as a general decrease in SST values is observed during the 16 days, the development and the persistence of a strong SST zonal gradient at about $40^{\circ} \mathrm{N}$ latitude are evident. This evolution could be partially explained by the verified presence of a large scale low atmospheric pressure centre over the study area during the $14^{\text {th }}$ and the $15^{\text {th }}$ of September. These conditions were reported also in the weather data collected by the WG, as a lowering in air pressure and temperature starting from the $12^{\text {th }}$ of September (Fig. 5). This atmospheric front hauled very cold air from Northern Europe over the southern TYS, influencing the sea surface layer tempera- 
ture (hereafter SLT) during the following days. Another evidence of the stability of the spatial patterns during the entire cruise can be confirmed by maps of SLA and ADT data with associated geostrophic currents, all provided by AVISO. Observing both variables is necessary because sometimes structures appearing in the SLA maps cannot be unequivocally associated with specific circulation features (Iacono et al., 2013). Information on the height change associated with the satellite observed mean circulation, called Mean Dynamic Topography (MDT), is needed to remove possible ambiguities. Adding the MDT to the SLA yields the ADT maps. Nonetheless, the MDT reconstruction has its own limitations and uncertainties which may locally obscure the information contained in the SLA especially in areas, such as the Mediterranean Sea, in which the circulation displays a strong seasonal cycle. Comparing the SLA and the ADT maps is indeed the solution to avoid any wrong interpretation.
Daily ADT and SLA maps, plotted every 3 days from the $11^{\text {th }}$ to the $26^{\text {th }}$ of September (Fig. 6 a and b, respectively), show the stable presence of a dipolar structure over the study area. Both parameters report a low sea level core that is identified in the eastern part of the basin, durably associated to two high sea level structures. The larger one is located near the northern coasts of Sicily while the second one lies at about $40^{\circ} \mathrm{N} / 14^{\circ} \mathrm{E}$, just west of the low SLA previously described.

In terms of circulation, two strong anticyclonic structures are located north of Sicily and off the Campania coast, sometimes combined into a unique wider gyre during the studied period. Along the Calabria coast a weaker cyclonic cell is noted, usually embedded between the two western anticyclones. The spatial pattern described by $\mathrm{SSH}, \mathrm{SST}$ and in situ WG data is consistent with typical September-October features of southeastern TYS circulation described through model simulations and seasonal
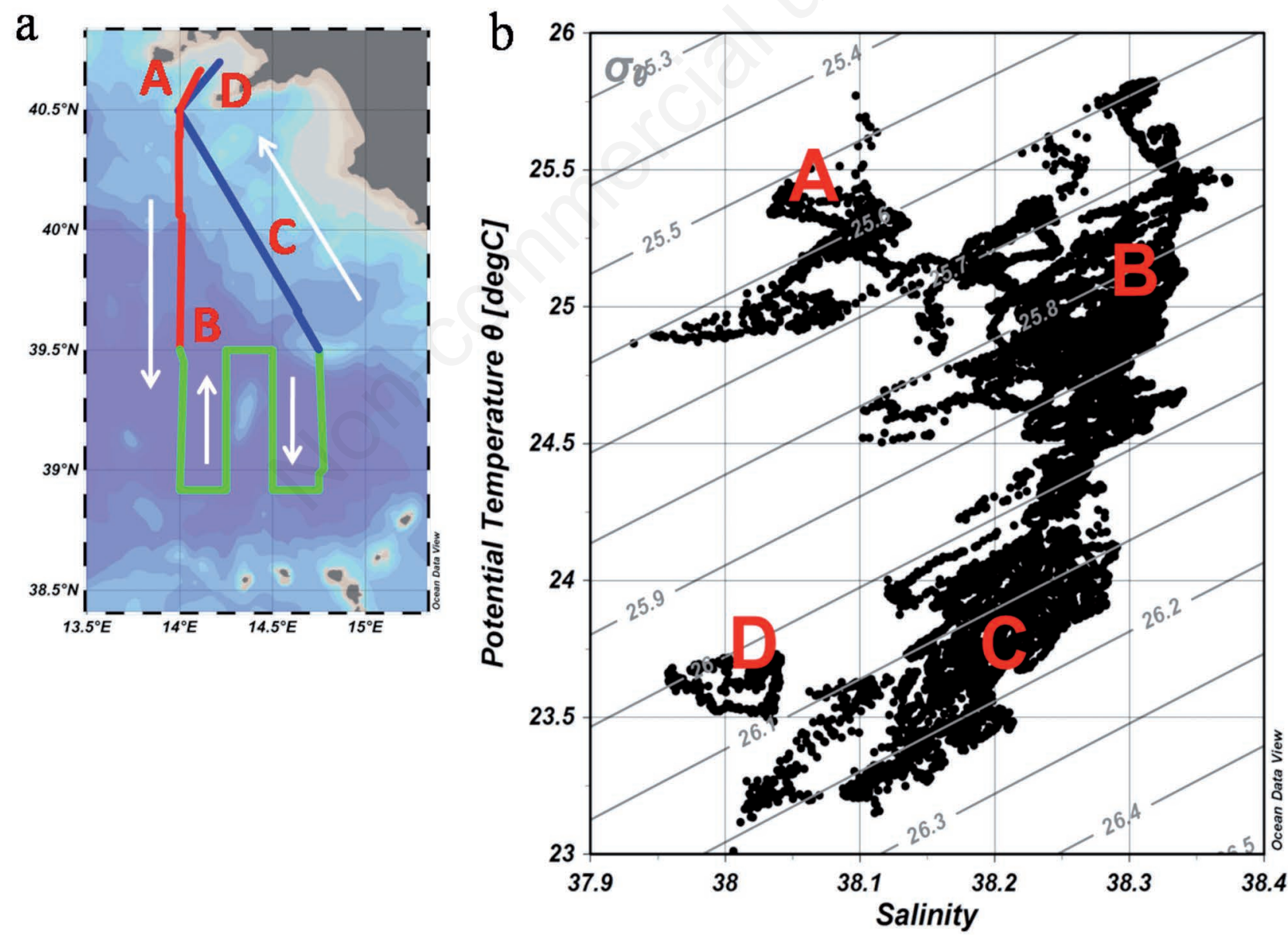

Fig. 3. Map (a) and $\theta / \mathrm{S}$ diagram (b) for the entire WG mission from the $12^{\text {th }}$ to the $26^{\text {th }}$ of September 2012 . WG track (blue line) and main heading (white arrows) are indicated. Correspondence between sub-regions and water masses properties is shown through capital letters. WG track color indicates L1 (red), L2 (green) and L3 (blue). 

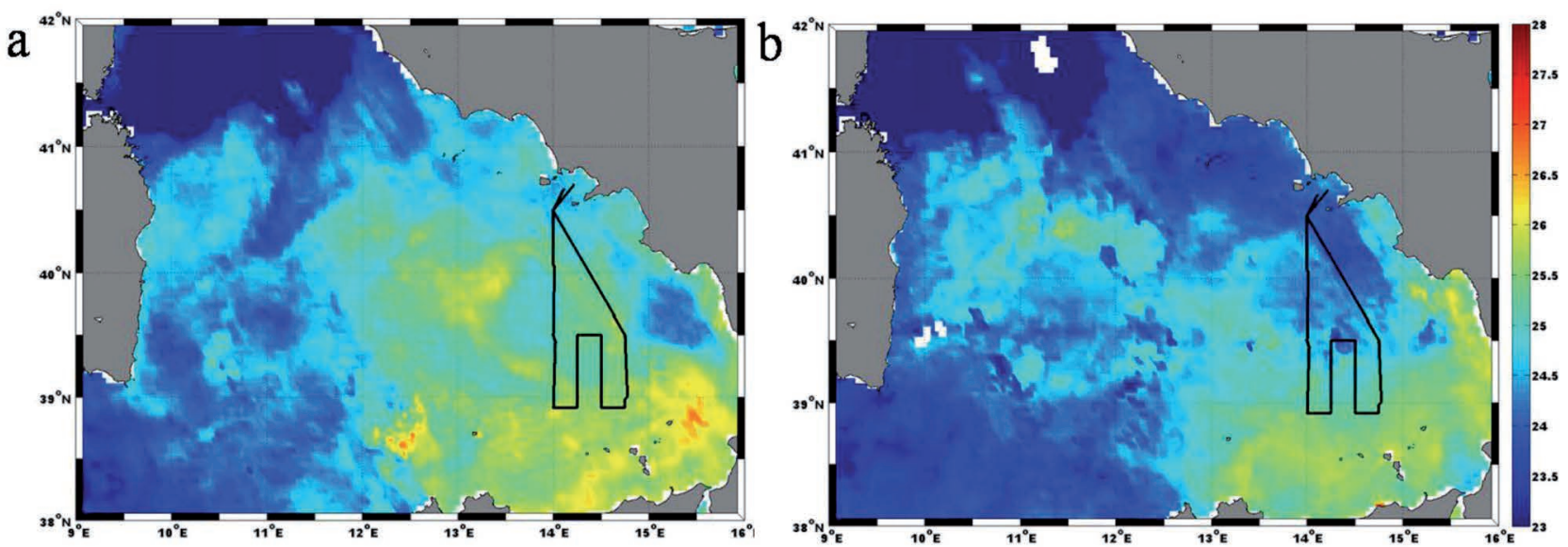

Fig. 4. MODIS AQUA level 3 SST maps $\left({ }^{\circ} \mathrm{C}\right)$ obtained by composites on 8 days for the periods $13^{\text {th }}$ to $20^{\text {th }}$ (a) and $21^{\text {st }}$ to $28^{\text {th }}($ b) September 2012. WG track is superposed (black line).

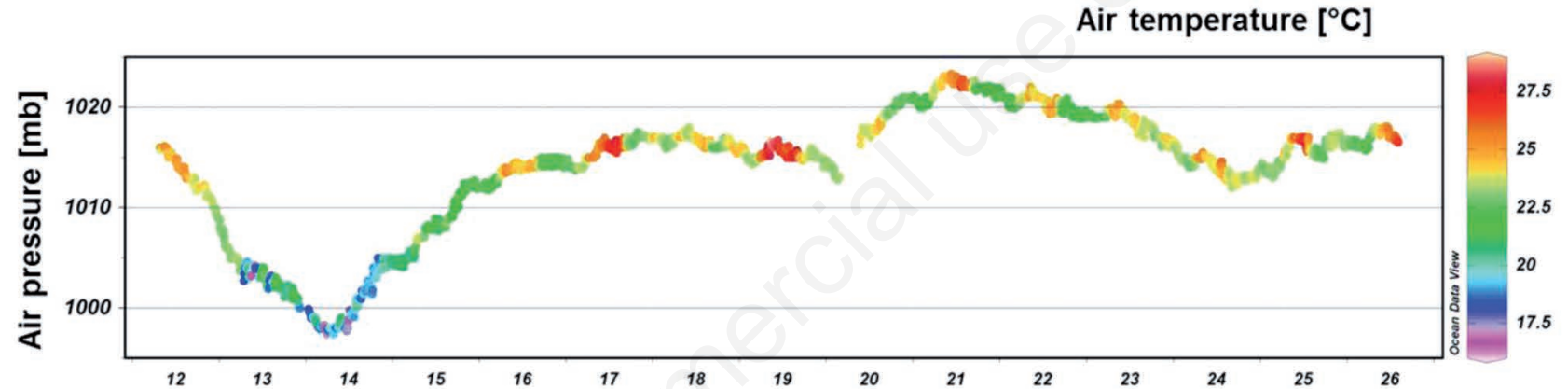

September 2012

Fig. 5. Air pressure (y-axis) and air temperature (color-scale) data collected by the WG weather station during the entire mission (12 $2^{\text {th }}$ to $26^{\text {th }}$ September 2012 on $\mathrm{x}$-axis).
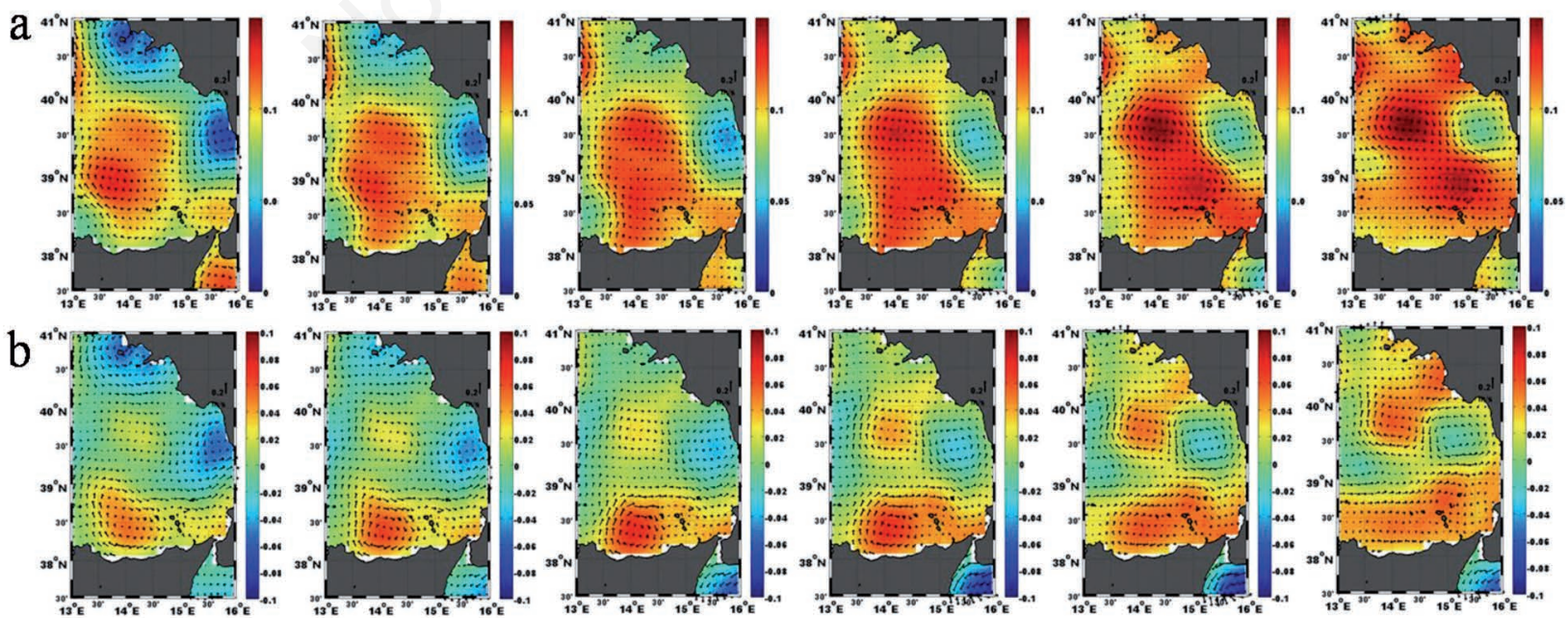

Fig. 6. Daily maps of AVISO Sea Level Anomaly (a) and Absolute Dynamic Topography (b), with superposed associated geostrophic velocities, in the southern TYS plotted every 3 days between the $11^{\text {th }}$ and the $26^{\text {th }}$ of September 2012. Campania, Calabria and Sicily regions are identified by squared numbers in Fig. 7. 
SLA and ADT maps (Iacono et al., 2013) as well as in previous studies based on cruise (Kryvosheya and Ovchinnikov, 1973) and drifter (Rinaldi et al., 2010) data.

The persistence of these structures and associated currents leads to the generation of a frontal area separating the different cores. In particular, the low sea level area near the Italian coast is separated from the northern high sea level structure by a strong gradient in ADT that reflects the SST gradient shown by MODIS satellite (Fig. 4) and WG data. Their persistence over the studied period might suggest that the observed eddies are not dependent on local forcing (i.e., weather conditions) and had a remote origin.

A qualitative comparison between AVISO ADT information and WG ADCP currents averaged over the sampled depths (10 m, $16 \mathrm{~m}, 26 \mathrm{~m}, 46 \mathrm{~m}$ and $66 \mathrm{~m})$ showed the presence of a fine correspondence between the two datasets. In Fig. 7 WG mean currents collected along the three transects have been superposed over the mean altimetric ADT map for the studied period. WG data have been subsampled to $1 / 5$ for a better graphical representation. ADCP data describe well the main anticyclonic structure identified from altimetry along the L1 (between $40^{\circ} \mathrm{N}$ and $39.5^{\circ} \mathrm{N}$ at $14^{\circ} \mathrm{E}$ ) and confirm the presence (be-

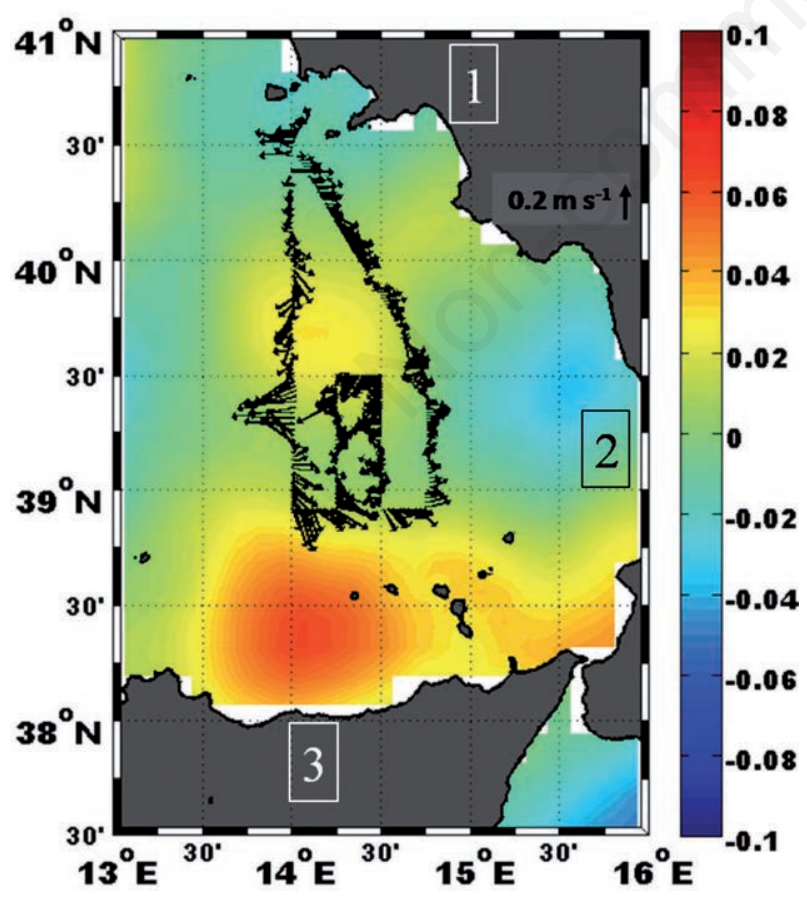

Fig. 7. Mean map of AVISO Absolute Dynamic Topography (color scale) for the $12^{\text {th }}$ to $26^{\text {th }}$ September period, with superposed corresponding WG in situ mean currents collected by ADCP between $-10 \mathrm{~m}$ and $-66 \mathrm{~m}$ depths (black arrows). Squared numbers identify Campania (1), Calabria (2) and Sicily (3) regions. tween $14^{\circ} \mathrm{E}$ and $14.7^{\circ} \mathrm{E}$ at $38.8^{\circ} \mathrm{N}$ ) of a consistent west to east current, flowing in the southwest corner of the L2, which hauls waters from the northern coast of Sicily. The edge of the eastern cyclonic vortex visible in the ADT maps is also identified by the counterclockwise velocities observed by WG in the northeastern edge of the L2 area (at $39.4^{\circ} \mathrm{N} / 14.7^{\circ} \mathrm{E}$ ). The observation of colder and fresher waters in this area (see also Fig. 10) is probably linked to the presence of the persistent cyclonic gyre already described off the Italian coast, and possibly to the associated upwelling processes. As stated before, these observations are totally consistent with previous eastern TYS circulation analyses confirming the presence of a persistent cyclonic vortex located at around $39.5^{\circ} \mathrm{N} 14.6^{\circ} \mathrm{E}$ (Rinaldi et al., 2010; Iacono et al., 2013).

Furthermore, high resolution WG mean currents have been compared to co-located $1 / 8^{\circ}$ resolution altimeter geostrophic velocities in order to assess the general current pattern of the study area. Fig. 8 compares: (a) WG ADCP mean currents in the layer between $10 \mathrm{~m}$ and 66 $\mathrm{m}$ depths and AVISO geostrophic velocities; and report their (b) zonal and (c) meridional components. Both dataset have been smoothed with a window-144 (corresponding to the number of WG current daily samples) running mean for a better graphical representation. When discussing these results, it is important to remark that the WG ADCP gives information concerning the mean current of the top 66 meters, while the altimeter provides an integrated current of the whole layer above the main pycnocline. This implies that WG data are partially influenced by ageostrophic dynamics due to wind. Near inertial currents, Ekman currents and internal tides all partially contribute to the observed in situ velocity too. Also, AVISO daily currents are post-processed products optimally interpolated with a time-decorrelation scale of two weeks while ADCP provides instantaneous data. Nonetheless, Fig. 8 shows that WG and altimetry observe a similar current pattern with a general fine correspondence, except than in part of the last transect of the WG campaign (L3). The analysis of the $u$ and $v$ components point out the expected higher resolution (smalls scales) captured by WG observations and a good correlation between the two dataset in terms of zonal and meridional components. Maximum differences between WG and satellite current components are $0.18 \mathrm{~m} \mathrm{~s}^{-1}$ and $0.12 \mathrm{~m} \mathrm{~s}^{-1}$ for $u$ and $v$ respectively. Nevertheless, a better correlation is remarkable in $u$ component. The differences noticed in L3 seems to be linked to a different behavior of the meridional components. As stated above, it is important to remark that all data represented in Fig. 8 have been smoothed with a window-144 filter. Since WG recorded an average platform velocity of about 0.9 knots, this implies a spatial smoothing at about $40 \mathrm{~km}$. Nevertheless, WG ADCP is able to resolve finer spatial scales as clearly visible in Fig. 7 and 
in the unfiltered $u$ and $v$ series (not shown). All these results confirm the importance of AVISO information in describing large scale patterns as well as the usefulness of WG in resolving small scale and local features of the ocean surface circulation.

A preliminary comparison between WG observations and Mediterranean Sea model output has been performed in order to confirm these results. ADCP measurements have been compared to co-located (in space and time) NEMO model daily mean horizontal velocities derived in the water column layer included between 11.55 and 66.45 $\mathrm{m}$ depth (Fig. 9a). Zonal $(u)$ and meridional (v) components are compared in Fig. 9 b and 9c, respectively. Datasets (both smoothed with a window-144 running mean) show an excellent correlation except in L1 where $v$ components seems to be opposite in phase. Nevertheless, $v$ components show a general better agreement and a lower maximum discrepancy $\left(0.14 \mathrm{~m} \mathrm{~s}^{-1}\right.$ versus $0.19 \mathrm{~m}$ $\mathrm{s}^{-1}$ ) than $u$ components. These results demonstrate the benefits of WGs in evaluating and/or complementing model outputs and suggest their combined use as a possible solution for achieving a large scale synoptic monitoring of the small mesoscale surface circulation that usually cannot be completely resolved by satellite altimetry.

In this overall scenario, even when merging in situ data from different places and time along the mission track, WG dataset seems to offer a reliable picture of the general physical pattern of the area (Fig. 10). WG SLT

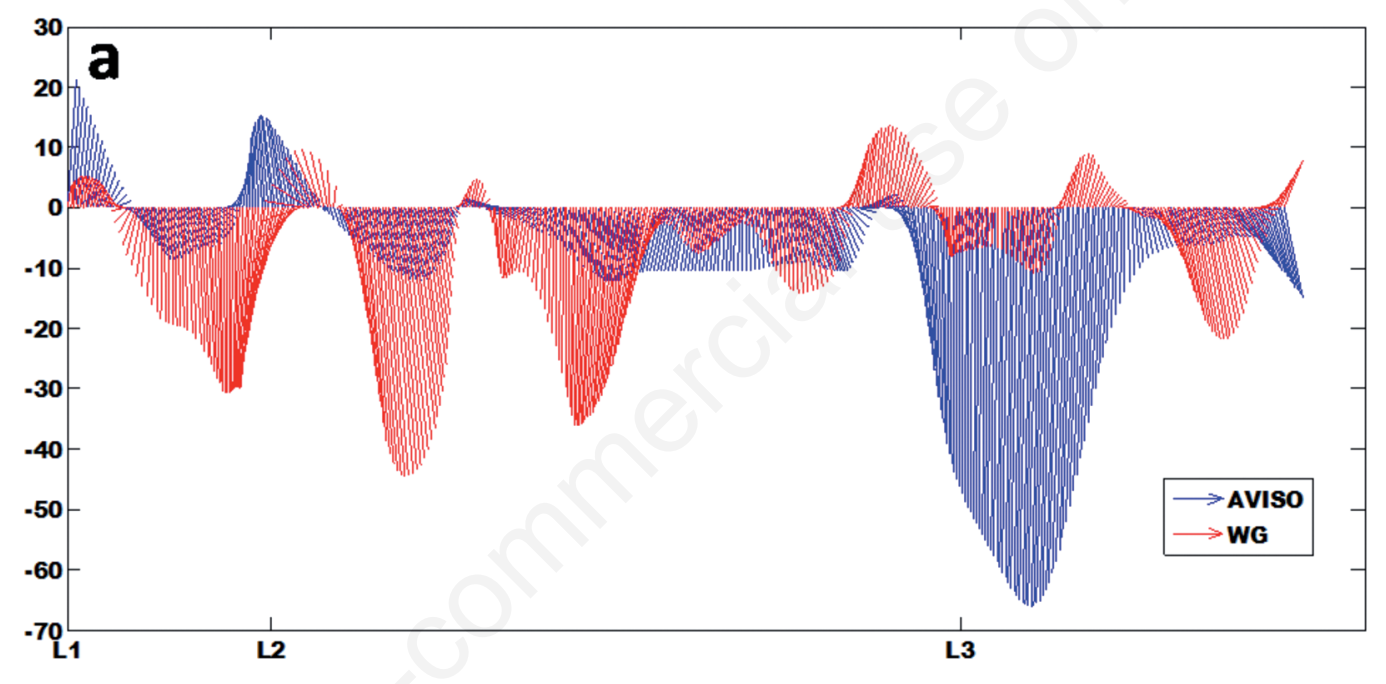

Current zonal component $-\mathbf{U}\left[\mathrm{m} \mathrm{s}^{-1}\right]$
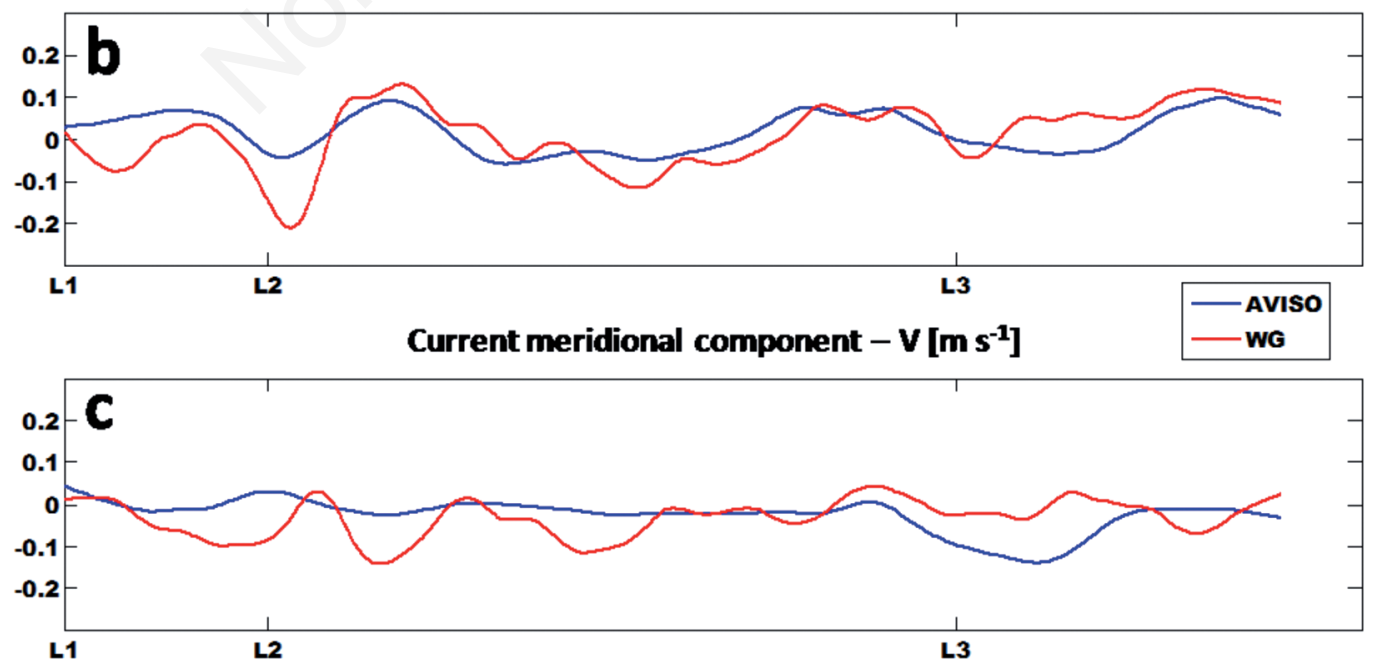

Fig. 8. Comparison between local WG mean currents (red) and altimeter geostrophic velocities at $1 / 8^{\circ}$ resolution (blue). WG ADCP mean currents in the layer between $10 \mathrm{~m}$ and $66 \mathrm{~m}$ depths and AVISO geostrophic velocities (a), and their zonal (b) and meridional (c) components are reported. 
observations collected from the $12^{\text {th }}$ to the $26^{\text {th }}$ of September describe the presence of a cold water vein in the eastern part of the study area with a low SLT core at $23.7^{\circ} \mathrm{C}$ (Fig. 10a). This relatively cold water is separated from a warmer water mass by a frontal structure located between $40.2^{\circ} \mathrm{N}$ at $14.2^{\circ} \mathrm{E}$ and $39.3^{\circ} \mathrm{N}$ at $15.0^{\circ} \mathrm{E}$. Furthermore, two warm SLT cores at $25.6^{\circ} \mathrm{C}$ and $25.3^{\circ} \mathrm{C}$ are observed at $40.0^{\circ} \mathrm{N} / 14.0^{\circ} \mathrm{E}$ and $39.1^{\circ} \mathrm{N} / 14.0^{\circ} \mathrm{E}$ respectively.

According to the $\theta-\mathrm{S}$ diagram, Figure $10 \mathrm{~b}$ points out the presence of a coast to open-sea haline gradient between the coastal area located north of $40.3^{\circ} \mathrm{N} / 14.0^{\circ} \mathrm{E}$ (salinity core at 38.1 ) and the open-sea region south of $40.0^{\circ} \mathrm{N}$ (salinity values higher than 38.2 ). As expected, lower values are observed inside the Gulf of Naples where rivers and inland supplies reduce the surface layer salinity down to 38.0. On the contrary, saltier waters are identified at the end of L1 where S values higher than 38.3 have been observed by the WG. This water mass possibly belongs to the external edge of the anticyclonic gyre persistently observed along the northern Sicilian coast (Fig. 6). Focusing on the Marsili Seamount sub-region (L2), we can distinguish interesting saltier/warmer and fresher/ colder water masses in the proximity of the southwestern and northeastern edges respectively (Fig. 10). Along the L3, fresher waters are observed in the area around $40.0^{\circ} \mathrm{N} / 14.4^{\circ} \mathrm{E}$.

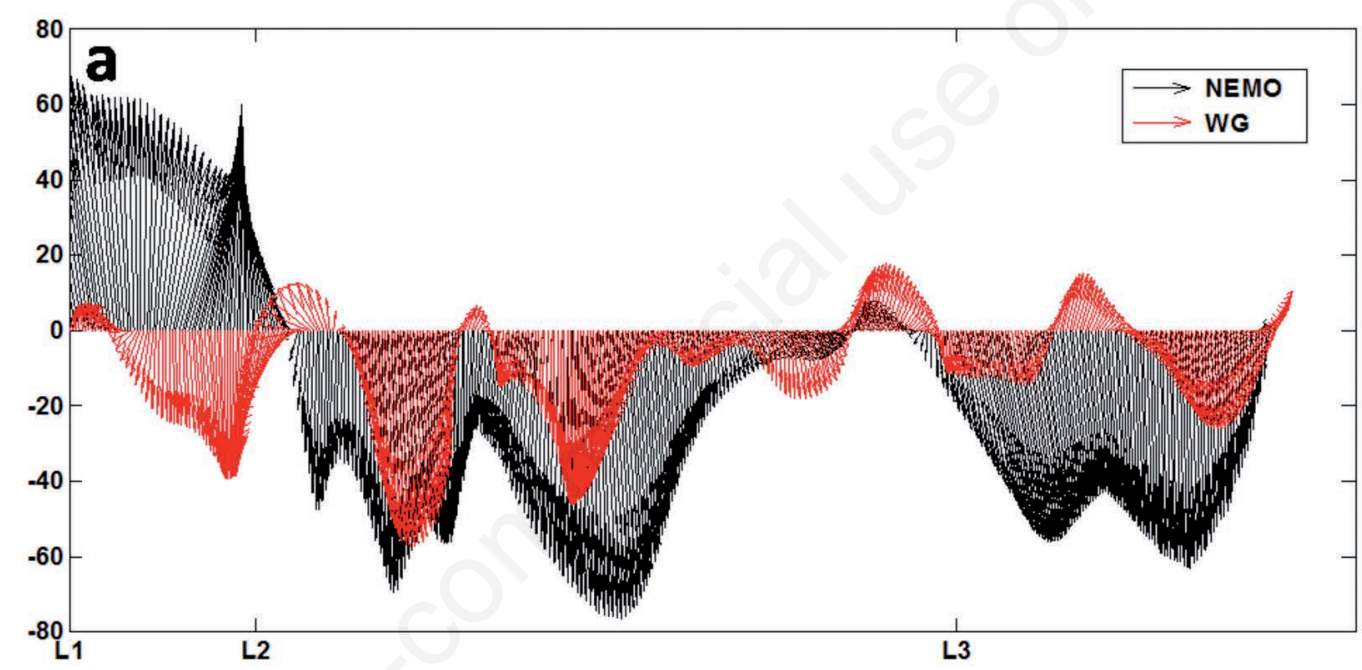

Current zonal component $-\mathrm{U}\left[\mathrm{m} \mathrm{s}^{-1}\right]$
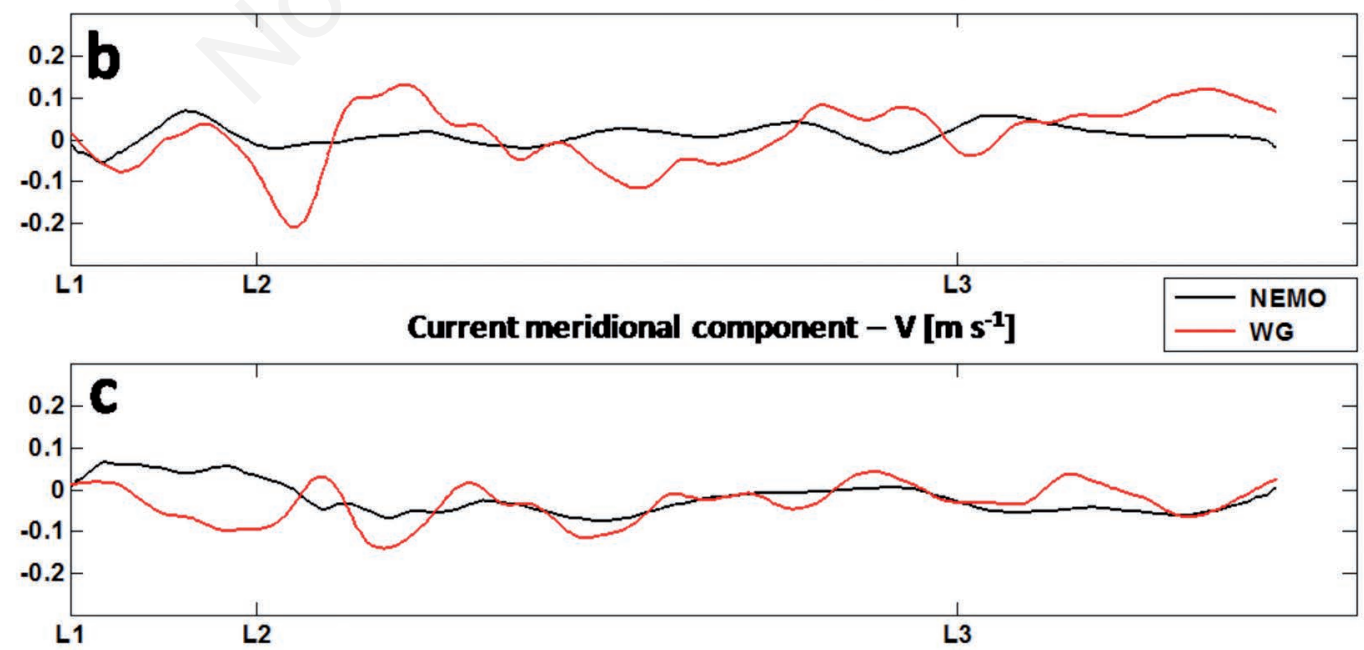

Fig. 9. Comparison between local WG mean currents (red) and modeled currents at $1 / 16^{\circ}$ resolution (black). WG ADCP mean currents in the layer between $10 \mathrm{~m}$ and 66m depths and NEMO model currents in the same layer (a), and their zonal (b) and meridional (c) components are reported. 


\section{Sea water optical properties}

The Turner C3 fluorometer observations are more challenging to interpret. Collected data are summarized in Fig. 11 where surface layer CDOM (a), refined fuels concentration (b) and turbidity (c) maps are shown in terms of RFU. As expected, a qualitative analysis of these data shows that a negative gradient is present for all the enquired parameters when the WG moves from inside the Gulf of Naples to open-sea. This is observed during both L1 and L3. No other significant patterns are evident along the WG track for CDOM and refined fuels concentrations, except for the relatively higher values observed in the northeastern corner of the Marsili Seamount sub-region, in correspondence of the cyclone-anticyclone system edge. As for the turbidity, the presence of a regional pattern similar to what observed in terms of surface circulation (see Figs. 7 and 10) is identified. Lower turbidity values are found where lower SLT and the cyclone structure have been observed, higher ones where the anticyclonic systems persist.

Nonetheless, in these data it is possible to identify the well-known diel cycle linked to chlorophyll fluorescence (Brand, 1982; Jacquet et al., 2002). Time series of CDOM and refined fuels show a sinusoidal behavior that is in phase with night-day turnover (not shown). Diel signal is more evident in CDOM dataset for almost the entire sampling period and, as expected, the diurnal maximum was in the form of increased positive scatter. Anyway, the design of the WG used for this mission supported a $\mathrm{C} 3$ sensor that is not protected from direct sunlight (i.e., in a pipe) and hence that can be influenced by shadow variability from the surface board. This causes a very high noise in the CDOM and refined fuels series. Our initial concept for $\mathrm{C} 3$ dataset was to use spiking in the turbidity data as a proxy for large particulate aggregates (Briggs et al., 2011; Villareal and Wilson, 2014). The turbidity data contains a certain amount of spiking suggestive of possible large particles, especially along the first leg of the WG mission. Highest values were registered in the proximity of the Gulf of Naples both at the beginning and the end of the mission (not shown). However, the $\mathrm{C} 3$ sensor responds to bubbles as well. This is a possible additional source of noise because many microbubbles are usually generated along the bottom of the float. For this reason, these spikes have been removed during the quality check procedures. There are several layers of complexity associated with comparing WG fluorescence and OC data, e.g. the pronounced diel rhythm identified in the collected data and the difference between surface and optical depth
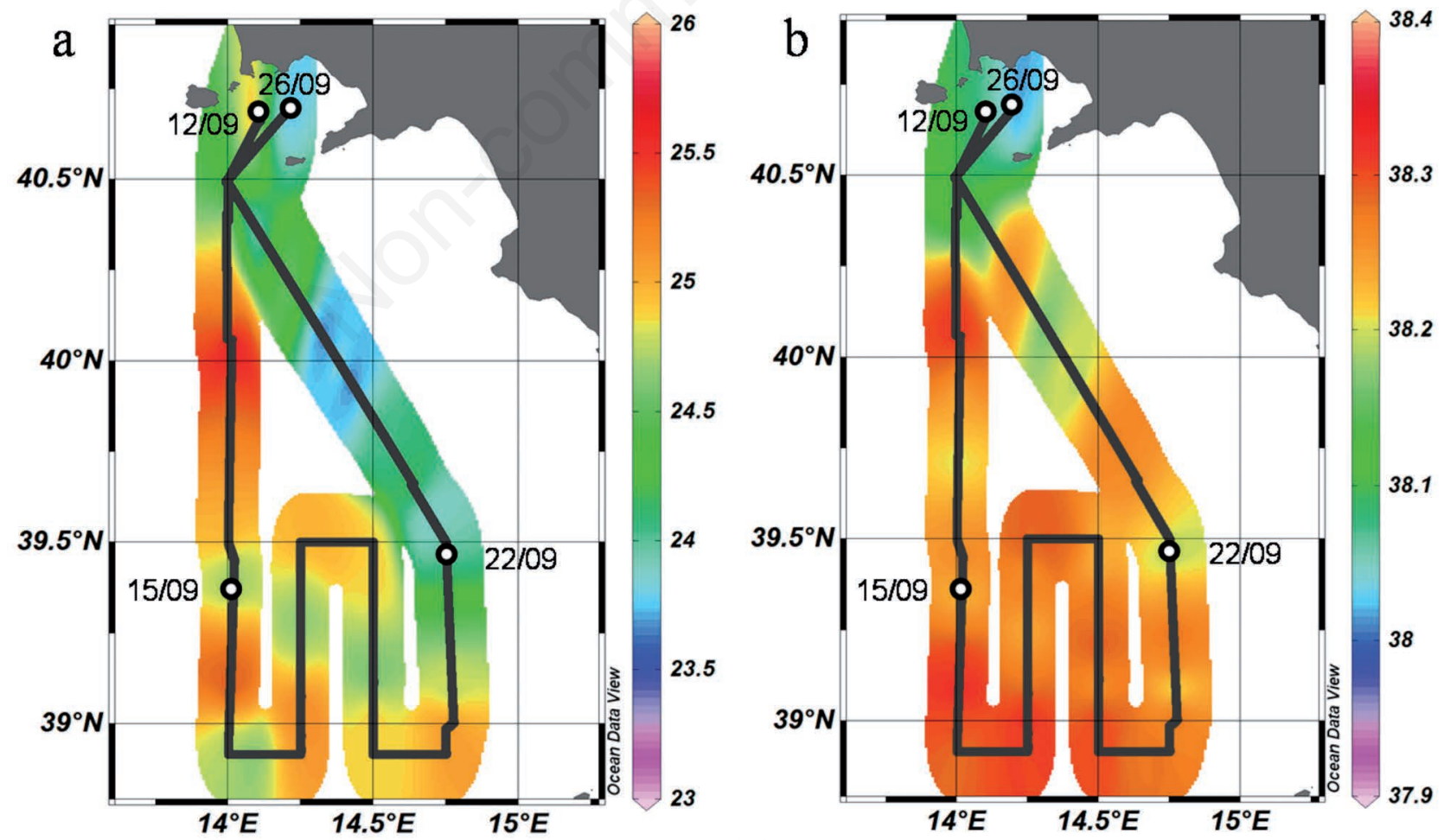

Fig. 10. Temperature (a) and salinity (b) overall mission WG observations collected between the $12^{\text {th }}$ and the $26^{\text {th }}$ of September 2012 along WG track (marked line). 
measurements (Villareal and Wilson, 2014). In general, the patterns observed in the satellite and WG datasets were in agreement (not shown) but calibration problems suggest caution in use of the fluorescence data. In particular, WG CDOM observations show a linear correlation of $\mathrm{R}=0.85$ and $\mathrm{R}=0.80$ with co-located (in space and time) OC chlor-a and chlor-ocx products respectively. Actually, $\mathrm{CDOM}$ and chlorophyll are different parameters but they both absorb light in the same spectral range so that it is difficult to differentiate between the two. The former absorbs light and decreases reflectance in the visible portion of the spectrum, especially in the blue region, while the latter strongly absorbs red and blue light and reflects green. This is the reason why water color usually changes from green at coastal region with higher chlorophyll and CDOM concentration to blue in deep waters where chlorophyll is the mainly water constituent. The correlation results achieved in this study confirm the importance of understanding the relative contribution of chlorophyll and CDOM dynamics to correctly detect trends in phytoplankton production.

Even though turbidity and refined fuel do not have a direct satellite equivalent, an attempt was done to compare WG data with MODIS derived information. WG turbidity data were compared with the Kd490 MODIS product which provides information about how strongly the light intensity is attenuated within the water column. It is directly related to the presence of scattering particles, either organic or inorganic, in the water column and thus it could give an indication of water clarity or of the water column turbidity. After selecting OC MODIS products suitable for the comparison, only 9 (among the 40 available) images passed the quality check (mostly because of the presence of clouds) and a very poor correlation was found $(\mathrm{R}=0.07)$ among MODIS based Kd490 product and WG turbidity measurements. This seems to indicate, for such a specific parameter, that the in situ and remote sensors are looking at dissimilar objects. A different depth of investigation and/or a small scale variability, that MODIS is not able to capture, could explain these results. It should be also underlined that, by its design, the WG is propelled at the surface like a surfboard and bubbles of all sizes will roll along the bottom of the float. As stated before, microbubbles are of particular concern since they will not rapidly ascend and are likely to represent a source of noise for the turbidity WG parameter (Villareal and Wilson 2014).

As for the comparison between WG refined fuels data and MODIS satellite products, the RST-OIL approach (Casciello et al., 2007, 2011, Grimaldi et al., 2009a, 2009b, 2011a, 2011b) was applied. Results showed that no intense oil spills were observed in either the WG data or the satellite observations.

\section{Sea surface temperature}

Among the parameters acquired by WG which could have been compared with satellite data, the SST is the only one that offered a major opportunity to be analyzed in details because both the technologies are able to provide comparable information.

First of all, it should be stressed that the measurements acquired by WG refer more to a bulk SST than a skin one. As already said, the CTD probe is located below the float, providing an information that is referred as an average at

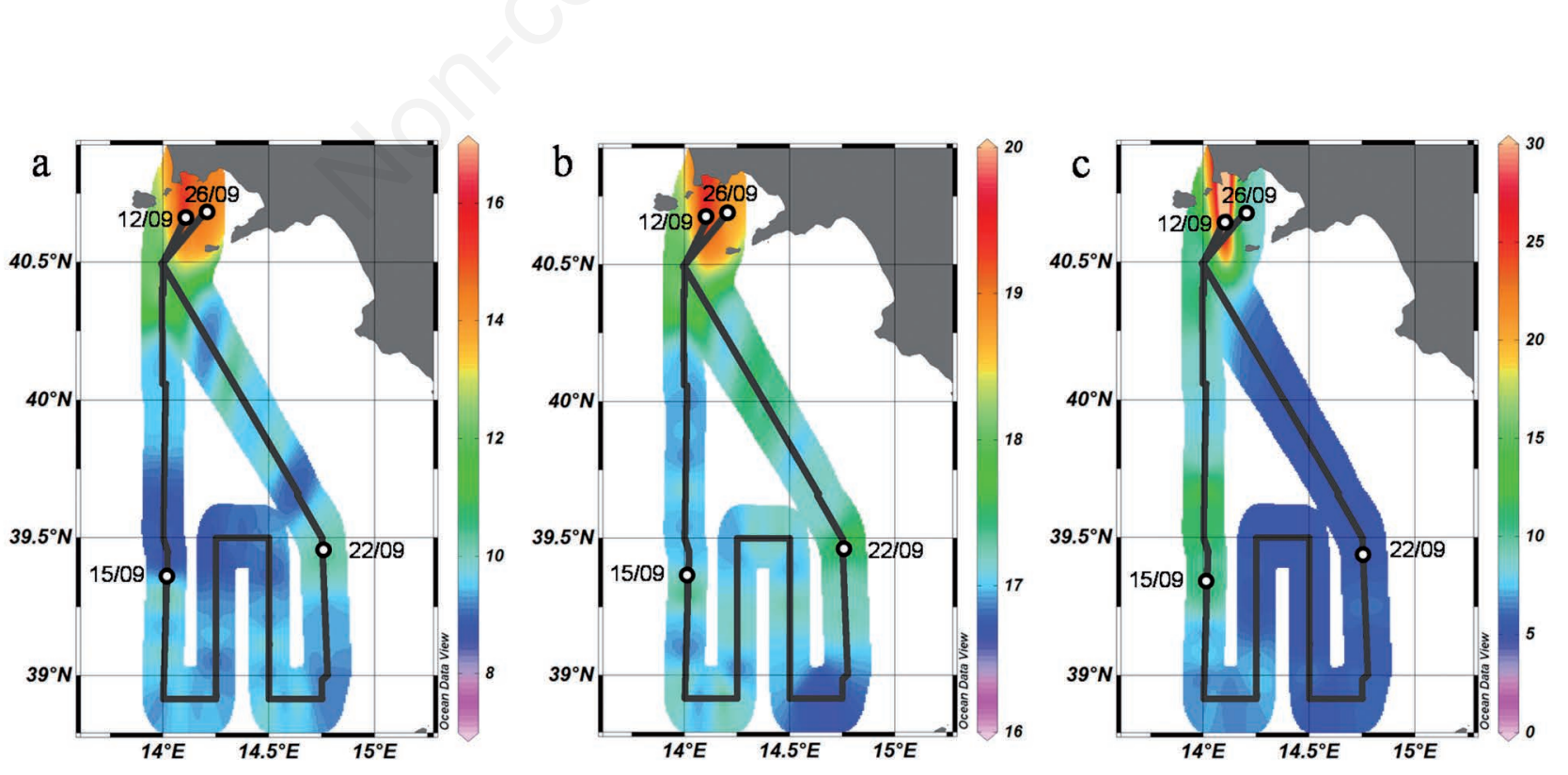

Fig. 11. CDOM (a) Refined fuels (b) and turbidity (c) overall mission observations collected by C3 sensor between the $12^{\text {th }}$ and the $26^{\text {th }}$ of September 2012 along the WG track (marked line). Values are expressed in terms of Relative Fluorescence Units (RFU). 
$5.8 \mathrm{~m}$ depth. On the other hand, the information provided by MODIS refer to a layer less than $1 \mathrm{~mm}$ thick at the ocean surface (Kilpatrick et al., 2015), namely to the skin temperature. Taking into account such a difference and the very short time duration of cruise (with a few MODIS passes all masked by clouds mainly during the first leg), the comparison has been mainly addressed to understand the potential of the WG in providing useful information about SST variability at a refined spatial scale.

In Fig. 12a the WG SST variation along its path is reported. Looking at this image, it is possible to note that SST variations at short-time scale are almost negligible, apart from two small portions acquired during the first leg of and at the end of the mission. Furthermore, it is also possible to see the daily SST variability, better highlighted in Fig. 12b where WG SST data distribution is reported. In this figure, a clear separation between the night-time (colder) data and the warmer day-time measurements is observable, with a larger range of variability (almost $2^{\circ} \mathrm{C}$ ) for diurnal data respect to the night-time ones (about $1.3^{\circ} \mathrm{C}$ ).

MODIS SST has been computed everywhere regardless the presence of clouds and marked with a quality flag (QF) indicating the accuracy of the SST information. To avoid cloud and cloud-edge pixel contamination in the following analysis, only MODIS SST data characterized by a small possibility of cloud presence (i.e., $\mathrm{QF} \leq 1$ ) have been considered. MODIS products which passed this filter have been co-located on the WG path (red segments in Fig. 12c). During such an operation, taking into account the above mentioned small variability of the WG SST at short-time scale, SST MODIS and WG SST temporal average computed in a time window of \pm 2 hours respect to the MODIS time acquisition have been compared. For this reason, MODIS data are represented by several red segments. In addition, the different lengths of the segments highlight the variable numbers of measurements acquired at changing speeds by the WG during the mission. Unfor-
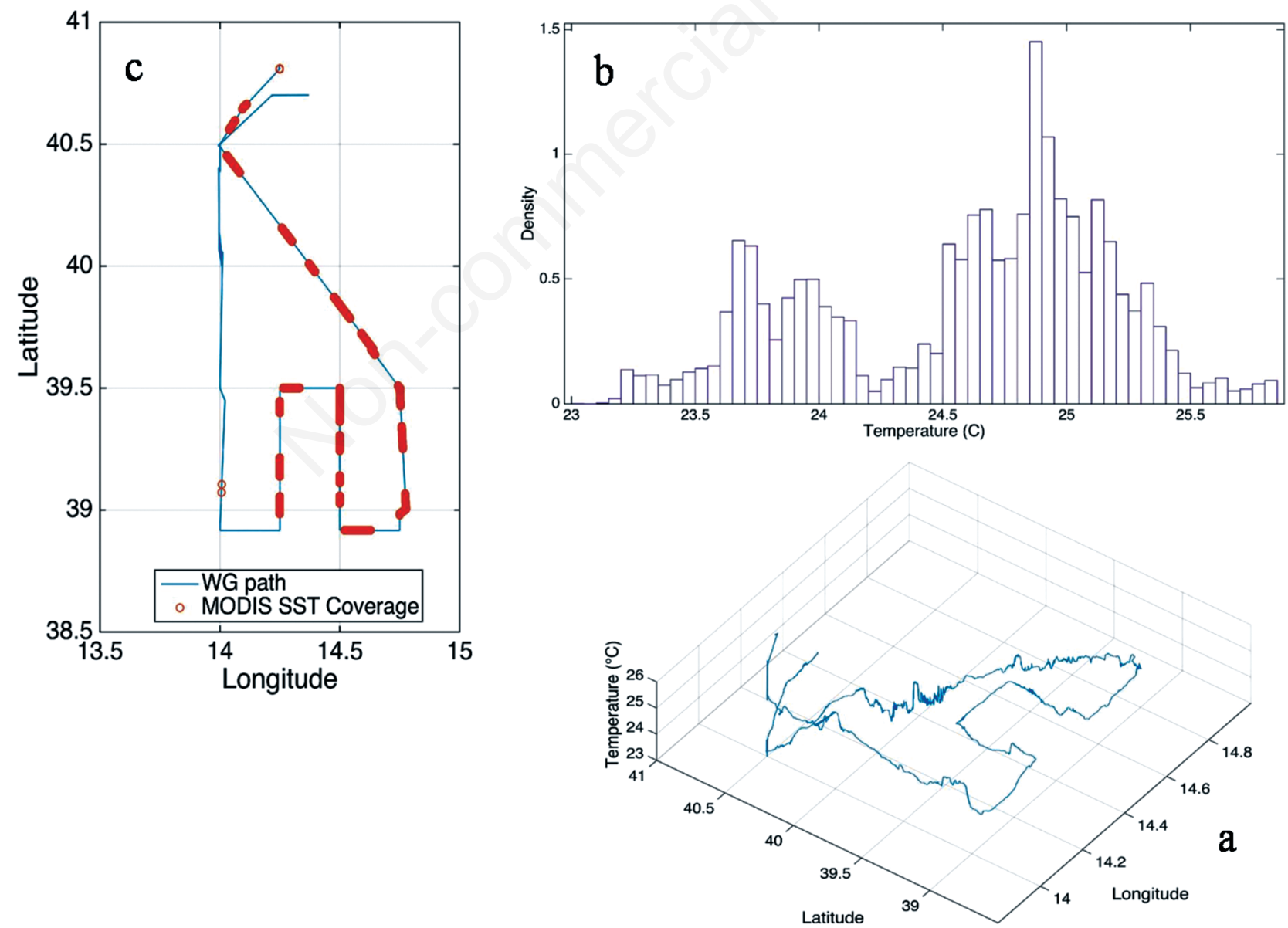

Fig. 12. SST variation as measured by WG during the mission (a) and its frequency distribution (b). In (c) the subsets where it was possible to perform the comparison between MODIS SST product and WG data are indicated with red segments along the WG path. 
tunately, as already said, no useful MODIS SST products were available during most of L1.

In Fig. 13 the SST Probability Density Function distributions of MODIS (purple line) and corresponding WG data (red line) have been compared. A good agreement between the two series is observed as well as a discrimination between day-time and night-time data and a similar variability. This result was further confirmed by carrying out a correlation analysis between WG and satellite products (Fig. 14). A coefficient of correlation (R) of 0.76 was achieved $\left(\mathrm{RMSE}=0.41^{\circ} \mathrm{C}\right)$, with a maximum discrepancy of $0.7^{\circ} \mathrm{C}$.

Nonetheless, it is important to remark that SST is a challenging parameter to define precisely as the upper ocean (i.e., the first $10 \mathrm{~m}$ ) has a complex and variable vertical temperature structure that is related to ocean turbulence and air-sea fluxes of heat, moisture and momentum. This is important to be considered when comparing (or merging) observations made by different satellites and in situ instruments that measures temperatures at depth of 10-20 $\mu \mathrm{m}$ (skin SST) and few meters (or centimeters) respectively. On the other hand, temperatures at all depths collapse to the same value before local sunrise. This value, free of diurnal temperature variability, is namely the SSTfnd, i.e. the temperature at the first time of the day when the heat gain from the solar radiation absorption exceeds the heat loss at the sea surface (Le Traon, 2011). Thus, WG SST measurements (red line) were compared with co-located (in space and time) CMEMS Level-3 near real time (blue line) and Level-4 reprocessed (black line) SSTfnd information (Fig. 15). All the datasets were smoothed with a window-144 (the number of analyzed WG daily samples) running mean. Results show a very good agreement with both products. Statistical analysis pointed out that WG measurements were more linearly correlated to Level-3 ultra-high resolution SST-fnd $\left(\mathrm{R}=0.89\right.$, $\mathrm{RMSE}=0.29$, maximum discrepancy of $\left.0.90^{\circ} \mathrm{C}\right)$ than to Level-4 reprocessed data $(\mathrm{R}=0.86, \mathrm{RMSE}=0.39$, maximum discrepancy of $1.29^{\circ} \mathrm{C}$ ). On the other hand, Level-3 values suffer the existence of data gaps due to bad weather conditions (mainly persistent cloud cover) that the optimal interpolation analysis applied to Level-4 products resolves without corrupting much the reliability of SSTfnd information. These results confirm the potential of the WG in giving back, at a refined spatial resolution, SST patterns which are consistent with the ones observed by satellite at a wider scale and coarser resolution.

\section{CONCLUSIONS}

The results derived by the WG mission performed between the $12^{\text {th }}$ and the $26^{\text {th }}$ of September 2012 in the Southern Tyrrhenian Sea, the first WG experiment in the Southern Mediterranean region, showed the value of WG measurements in the framework of a multiplatform, in situ and satellite based, monitoring system of sea surface parameters. Nonetheless, they draw attention to the existence of several limits in the combined use of satellite and WG observations, stressing the necessity of further analyses concerning the monitoring of the ocean optical properties.

Temperature, salinity, currents, CDOM, turbidity and refined fuels were observed and monitored in the area comprised between the Gulf of Naples and the Marsili Seamount.

The variability observed along the WG cruise in terms of water mass properties showed a decrease in temperature in agreement with expected variation due to the changing weather conditions observed during the 15 days survey. WG observations pointed out the presence of a

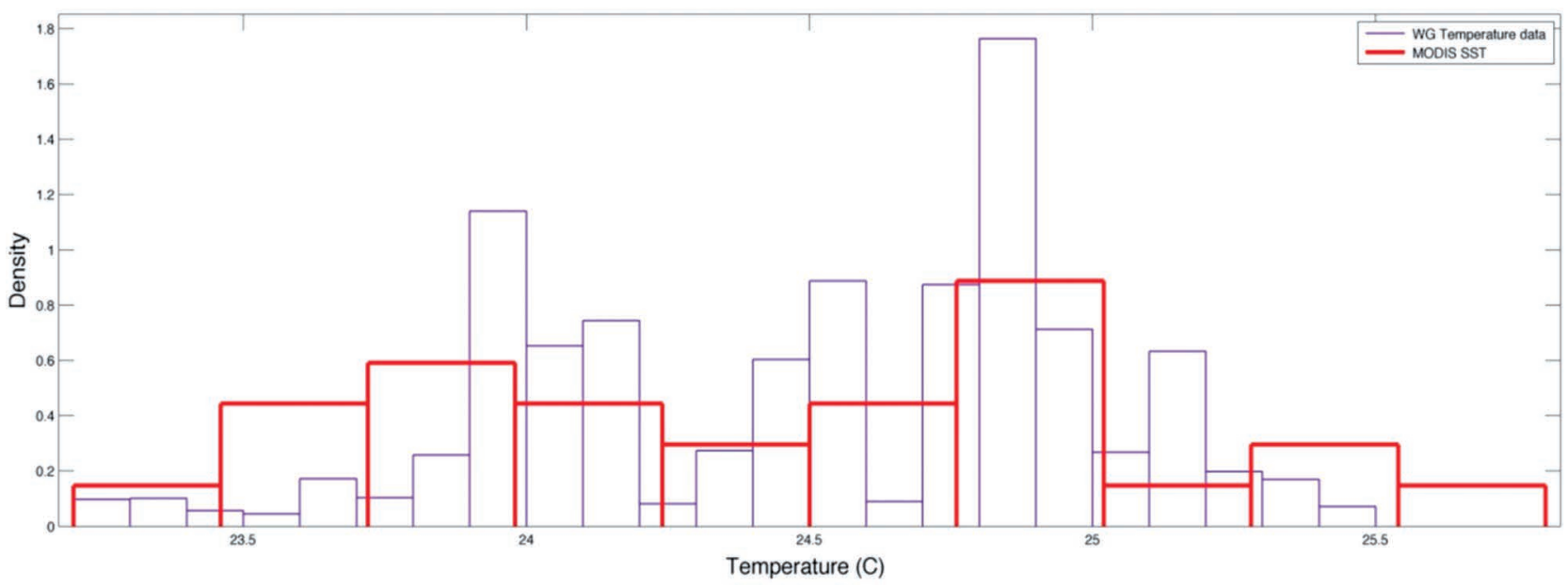

Fig. 13. Frequency distribution of MODIS SST data (purple line) overlapped on that of the corresponding WG data (red line). 

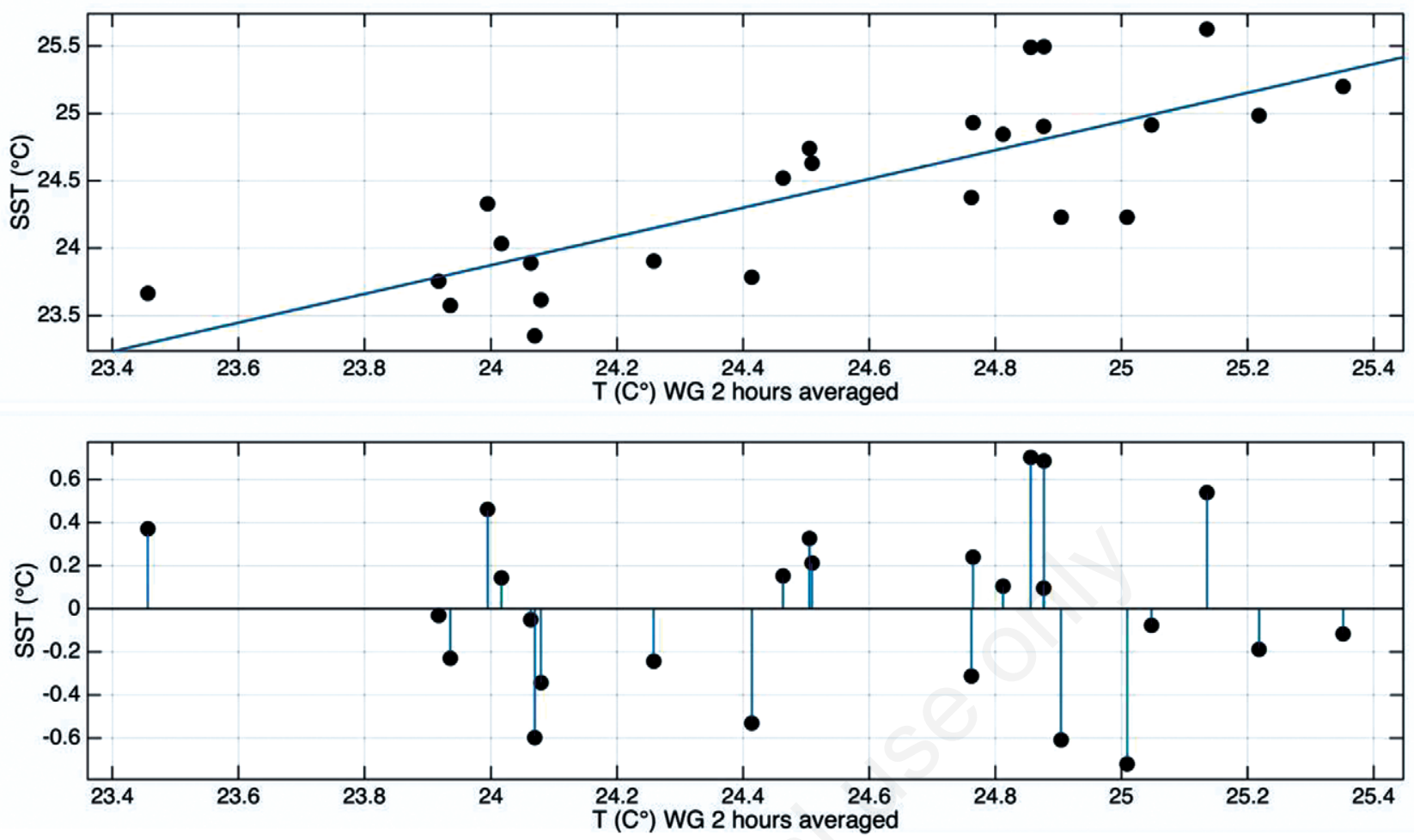

Fig. 14. Correlation between \pm 2 hours averaged WG SST data and MODIS SST products considering both day- and night-time data (top); residuals diagram (bottom).

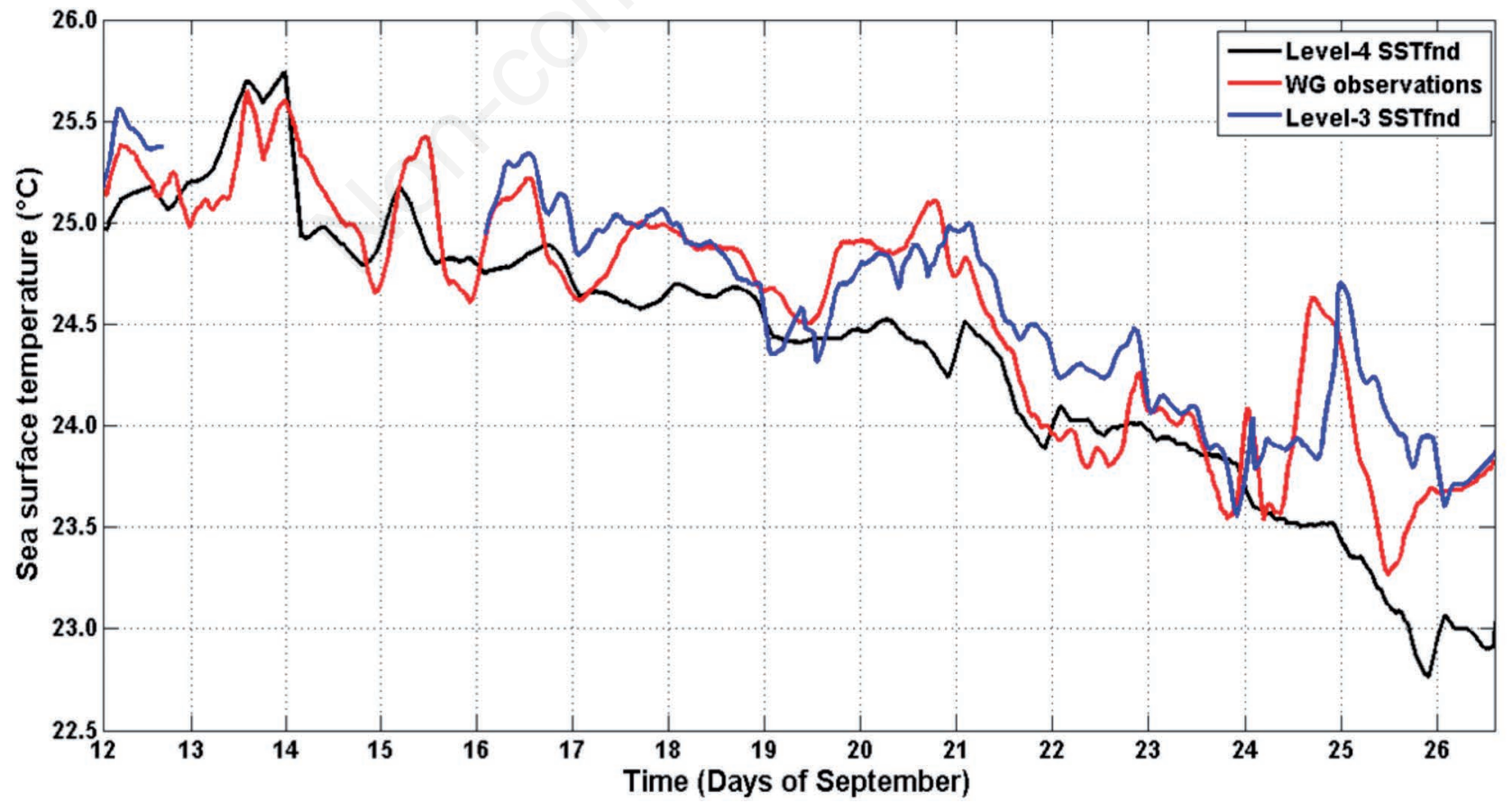

Fig. 15. Comparison between WG SST data (red line) and CMEMS Level-3 ultra-high resolution (blue line) and Level-4 reprocessed SSTfnd products during the WG mission. 
colder coastal water mass in the eastern part of the study area and a typical coastal to open-sea haline gradient. Most of the WG data were coupled with equivalent, or near-equivalent, satellite measurements. Surface layer currents and sea surface temperature compared well to AVISO and MODIS information respectively, detecting a general pattern of SSH and SST that remains quite stable during the WG survey. The qualitative comparison between AVISO geostrophic velocities and ADCP currents in the first 66 meters of the water column assessed the presence of a fine correspondence between the two datasets, confirming the usefulness of WG in observing local surface ocean circulation. A correlation analysis between WG and MODIS co-located data confirmed that WG information, even if acquired at 5.8 meters depth, can be used in a first instance to provide information about surface temperature variability. The results showed a correlation coefficient of 0.76 (with a maximum discrepancy of $0.7^{\circ} \mathrm{C}$ ) and a good agreement was found overlapping SST Probability Density Function distribution of MODIS and WG data. Nevertheless, this study suffered from the lack of continuous temperature measurements along the very first meters of the water column. During subsequent missions it would be useful to equipe the WG with a specific system (i.e., a chain of high resolution thermistors) in order to complete and inter-validate surface temperature information provided by satellite (skin and sub-skin) and CTD (subsurface) observations. Optical properties, instead, were more challenging to interpret and the in situ and remote sensed measurements were more poorly correlated. As for the turbidity, the absence of correlation with MODIS products possibly indicate that the two sensors were looking at different depths of investigation, or at different scale of variability, for such a specific parameter. Finally, no significant traces of refined fuels have been detected along the WG track. This implies the necessity to properly select testing areas (in order to include a higher range of variation of fuel content in the testing areas) to better asses WG $\mathrm{C} 3$ sensors sensitivity as well as the satellite techniques used for wide scale monitoring purposes. Moreover, the opportunity to relocate the $\mathrm{C} 3$ sensors in a proper position in order to avoid the direct effect of sunlight should be considered. Actually, LRI already dealt with some of these problems in the last few years. Since this mission, WG technology moved to SV3 version mounting a pumped $\mathrm{C} 3$ fluorometer system which limits most of the diurnal and bubbling issues seen in this study. WG-SV3 has a lot more battery and propulsion capability too and give the users the opportunity to choice an optional configuration with a thermistors chain that can be attached to the subsurface board umbilical for measuring the full depth of temperature in the surface ocean. It is important to remark that $\mathrm{C} 3$ observations should always be calibrated against measurements of chlorophyll-a from water samples co-located with the fluorometer. Considering that such measurements are not practical during long autonomous missions, WG users should find solution for optimizing pre- and post-deployment calibrations (i.e., using formal computational algorithms for determining drift in the sensor signal). Nonetheless, these results confirm the usefulness and the cost efficient strategy of a combined monitoring that involves both satellites, classical oceanographic observations and autonomous vehicles. In particular, a valuable strategy should involve large scale satellite observations for monitoring the study region and identifying the precise target areas, where WGs could realize high resolution observations with unique critical time and length scales, more than providing validation dataset. On the other hand classical in situ measurements, especially for optical properties, and modelling products are still advisable for validation purposes. The sensitivity to diel rhythms in WG fluorescence products suggests that physiological information is possible to obtain with the appropriate sensors and calibrations. As for SST, statistical analysis pointed out also that WG measurements were more linearly correlated to Level-3 ultrahigh resolution SST-fnd than to Level-4 reprocessed data. The fine results concerning the monitoring of the surface ocean currents achieved from the comparison between WG ADCP and NEMO products demonstrate the usefulness of WGs and suggest their combined use as a possible solution for achieving a large scale synoptic monitoring of the small mesoscale surface circulation that usually cannot be completely resolved by satellite altimetry. Additional compared analyses between WG ADCP / CTD data collected during this experiment and a dedicated ultra-high-resolution model will also be performed in a forthcoming study in order to better describe the southern Tyrrhenian Sea circulation and hydrology. In that study, WG ADCP data at single depths and full spatial resolution will be coupled with co-located model data at the same specific depths to obtain additional detailed information about the advantages and the limits of the use of WGs in evaluating and/or complementing model outputs.

\section{ACKNOWLEDGMENTS}

This study was performed in the framework of the RITMARE (la Ricerca ITaliana per il MARE) Flagship Project funded by the Italian Ministry of University and Research. It has been also partly supported by the PO FESR BASILICATA 2007-2013 in the framework of the project IOnian Sea water quality MOnitoring by Satellite data (IOSMOS). The altimeter products were produced by Ssalto/Duacs and distributed by Aviso, with support from Cnes (http://www.aviso.altimetry.fr/duacs/). MODIS data were obtained from NASA/GSFC OCEANCOLOR web site (http://oceancolor.gsfc.nasa.gov). We acknowl- 
edge the support provided by Liquid Robotics Inc. and Communication Technology Srl for Wave Glider operations and piloting and the important contribution in the analyses of MODIS products provided by Emanuele Ciancia at National Research Council Institute of Methodologies for Environmental Analysis.

\section{REFERENCES}

Artale V, Astraldi M, Buffoni G, Gasparini GP, 1994. Seasonal variability of gyre-scale circulation in the northern Tyrrhenian sea. J. Geophys. Res. 99:14127-14137.

Astraldi M, Gasparini GP, 1994. The seasonal characteristics of the circulation in the Tyrrhenian Sea. In: Seasonal and Interannual Variability of the Western Mediterranean Sea, Coastal and Estuarine Studies, Geophys. Monogr., Amer. Geophys. Union, 46:115-134.

Astraldi M, Gasparini GP, Sparnocchia S, Moretti M, Sansone E, 1996. The characteristics of the water masses and the water transport in the Sicily Channel at long time scales. Bull. Instit. Oceanogr. 17:95-116

Astraldi M, Gasparini GP, Vetrano A, Vignudelli S, 2002. Hydrographic characteristics and interannual variability of water masses in the central Mediterranean: a sensitivity test for long-term changes in the Mediterranean Sea. Deep-Sea Res. Pt. I 49:661-680.

Beatman L, Anderson T, Fong D, Jha R, 2013. Wave Glider ${ }^{\circledR}$ Integrated Sensor Validation Report: Teledyne RD Instruments Workhorse Monitor ADCP. Technical Report, Copyright ${ }^{\circ}$ Liquid Robotics, Inc., Sunnyvale, CA, USA.

Brand LE, 1982. Persistent diel rhythms in the chlorophyll fluorescence of marine phytoplankton species. Mar. Biol. 69:253-262.

Briggs N, Perry MJ, Cetinic I, Lee C, D’Asaro E, Gray AM, Rehm E, 2011. High-resolution observations of aggregate flux during a sub-polar North Atlantic spring bloom. DeepSea Res. Pt. I 58:1031-1039.

Budillon G, Gasparini GP, Schroeder K, 2009. Persistence of an eddy signature in the central Tyrrhenian basin. Deep-Sea Res. Pt. II 56:713-724.

Buongiorno Nardelli B, Tronconi C, Pisano A, Santoleri R, 2013. High and ultra-high resolution processing of satellite sea surface temperature data over southern European Seas in the framework of MyOcean project. Rem. Sens. Env. 129:1-16.

Casciello D, Lacava T, Pergola N, Tramutoli V, 2007. Robust Satellite Techniques (RST) for oil spill detection and monitoring. Proc. IV Int. Workshop on the Analysis of Multitemporal Remote Sensing Images, Leuven, Belgium. IEEE, doi: 10.1109/multitemp.2007.4293040.

Casciello D, Lacava T, Pergola N, Tramutoli V, 2011. Robust Satellite Techniques (RST) for oil spill detection and monitoring using AVHRR Thermal Infrared bands. Int. J. Remote Sens. 32:4107-4129.

Chapman CC, Haidvogel DB, 1992. Formation of Taylor caps over a tall isolated seamount in a stratified ocean. Geophys. Astrophys. Fluid. Dyn. 64:31-65.

Cotroneo Y, Aulicino G, Ruiz S, Pascual A, Budillon G, Fusco G, Tintoré J, (2015). Glider and satellite high resolution monitoring of a mesoscale eddy in the Algerian basin: Eeffects on the mixed layer depth and biochemistry. J. Mar. Syst. (In press). doi: 10.1016/j.jmarsys.2015.12.004

Fitzpatrick P, Lau Y, Moorhead R, Skarke A, Merritt D, Kreider K, Brown C, Carlon R, Hine G, Lampoudi T, Leonardi AP, 2014. A review of the 2014 Gulf of Mexico Wave Glider field program. Mar. Technol. Soc. J. 49:64-71.

Fusco G, Artale V, Cotroneo Y, Sannino G, 2008. Thermohaline variability of Mediterranean Water in the Gulf of Cadiz, 1948-1999. Deep-Sea Res. Pt. I 55:1624-1638.

Fusco G, Manzella GMR, Cruzado A, Gacic M, Gasparini GP, Kovacevic V, Millot C, Tziavos C, Velasquez ZR, Walne A, Zervakis V, Zodiatis G, 2003. Variability of mesoscale features in the Mediterranean Sea from XBT data analysis. Ann. Geophys. 21:21-32.

Goebel NL, Frolov S, Edwards CA, 2014. Complementary use of Wave Glider and satellite measurements: Description of spatial decorrelation scales in Chl-a fluorescence across the Pacific basin. Methods Oceanogr. 10:90-103.

Grimaldi CSL, Casciello D, Coviello I, Lacava T, Pergola N, Tramutoli V, 2011a. An improved RST approach for timely alert and Near Real Time monitoring of oil spill disasters by using AVHRR data. Nat. Hazards Earth Syst. Sci. 11:1281-1291.

Grimaldi CSL, Coviello I, Lacava T, Pergola N, Tramutoli V, 2009a. Near real time oil spill detection and monitoring using satellite optical data. Proc. Geoscience and Remote Sensing Society Symp. IEEE International 2009 - IGARSS 2009, Cape Town, 4:709-712.

Grimaldi CSL, Coviello I, Lacava T, Pergola N, Tramutoli V, 2009b. RST-based oil spill detection and monitoring by using optical data. pp. 323-330 in Proc. V Int. Workshop on the Analysis of Multi-temporal Remote Sensing Images, University of Connecticut, Storss.

Grimaldi CSL, Coviello I, Lacava T, Pergola N, Tramutoli V, 2011b. A new RST-based approach for continuous oil spill detection in TIR range: the case of the Deepwater Horizon platform in the Gulf of Mexico. In: Y. Liu, A. Macfadyen, Z.-G. Ji and R.H. Weisberg (eds), Monitoring and modeling the Deepwater Horizon oil spill: a record-breaking enterprise. American Geophysical Union, Washington, 195:19-31.

Hine R, Willcox S, Hine G, Richardson T, 2009. The Wave Glider: A wave-powered autonomous marine vehicle. Proc. of MTS/IEEE OCEANS 2009, Biloxi, MS.

Hopkins TS, 1988. Recent observations on the intermediate and deep water circulation in the southern Tyrrhenian Sea. Oceanologica Acta Special Issue (0399-1784):41-50.

Hu C, Lee Z, Franz, BA, 2012. Chlorophyll-a algorithms for oligotrophic oceans: A novel approach based on three-band reflectance difference. J. Geophys. Res. 117:C01011.

Iacono R, Napolitano E, Marullo S, Artale V, Vetrano A, 2013. Seasonal variability of the Tyrrhenian Sea surface geostrophic circulation as assessed by altimeter data. J. Phys. Oceanogr. 43:1710-1732.

Jacquet S, Prieur L, Avois-Jacquet C, Lennon JF, Vaulot D, 2002. Short-timescale variability of picophytoplankton abundance and cellular parameters in surface waters of the Alboran Sea (western Mediterranean). J. Plankton Res. 24:635-651.

Kilpatrick KA, Podestá G, Walsh S, Williams E, Halliwell V, Szczodrak M, Brown OB, Minnett PJ, Evans R, 2015. A 
decade of sea surface temperature from MODIS. Remote Sens. Environ. 165:27-41.

Krivosheya VG, 1983. Water circulation and structure in the Tyrrhenian Sea. Oceanology 23:166-171.

Krivosheya VG, Ovchinnikov IM, 1973. Peculiarities in the geostrophic circulation of the water of the Tyrrhenian Sea. Oceanology 13:822-827.

Le Traon PY, 2011. Satellites and operational oeanography. In: A. Schiller and G.B. Brassington (eds.), Operational oceanography in the 21st century. Springer-Verlag Berlin.

Marullo S, Santoleri R, Bignami F, 1994. The surface characteristics of the Tyrrhenian Sea: Historical satellite data analysis. In: Seasonal and Interannual Variability of the Western Mediterranean Sea, Coastal and Estuarine Studies. Geophys. Monogr. American Geophysical Union, Washington 46:135-154.

Millot C, 1987. Circulation in the Western Mediterranean Sea. Oceanologica Acta 10:143-149.

Millot C, 1999. Circulation in the Western Mediterranean Sea. J. Mar. Syst., 20:423-442.

Millot C, Candela J, Fuda JL, Tber Y, 2006. Large warming and salinification of the Mediterranean outflow due to changes in its composition. Deep-Sea Res. Pt. I 53:655-666.

Morel A, Gentili B, 2009. A simple band ratio technique to quantify the colored dissolved and detrital organic material from ocean color remotely sensed data. Remote Sens. Environ. 113:998-1011.

Oddo P, Adani M, Pinardi N, Fratianni C, Tonani M, Pettenuzzo D, 2009. A Nested Atlantic-Mediterranean Sea General Circulation Model for Operational Forecasting. Ocean Sci. Discuss. 6:1093-1127.

O'Reilly JE O'Brien MC, Siegel DA, Toole D, Menzies D, Smith RC, Mueller JL, Mitchell BG, Kahru M, Chavez FP, Strutton P, Cota GE, Hooker SB, McClain CR, Carder KL, Harding L, Magnuson A, Phinney D, Moore GE, Aiken J, Arrigo KR, Letelier R, Culver M, 2000. SeaWiFS postlaunch calibration and validation analyses, Part 3. NASA Technical Memorandum 2000-206892, vol. 11., NASA Goddard Space Flight Center: 49 pp.

Pascual A, Pujol MI, Larnicol J, LeTraon PY, Rio MH, 2007. Mesoscale mapping capabilities of multisatellite altimeter missions: first results with real data in the Mediterranean Sea. J. Mar. Syst. 65:190-211.

Pierini S, Simioli A, 1998. A wind-driven circulation model for the Tyrrhenian sea area. J. Mar. Syst. 18:161-178.

Poulain PM, Zambianchi E, 2007. Near surface circulation in the central Mediterranean Sea as deduced from Lagrangian drifters in the1990s. Cont. Shelf Res. 27:981-1001.

Rinaldi E, Buongiorno Nardelli B, Zambianchi E, Santoleri R, Poulain PM, 2010. Lagrangian and Eulerian observations of the surface circulation in the Tyrrhenian Sea. J. Geophys. Res. 115:C04024.

Rio MH, Poulain PM, Pascual A, Mauri E, Larnicol G, Santoleri R, 2007. A Mean Dynamic Topography of the Mediterranean Sea computed from altimetric data, in-situ measurements and a general circulation model. J. Mar. Syst. 65:484-508.

Teledyne, 2011. Acoustic Doppler Current Profiler principle of operation - A practical primer. Teledyne, Poway: $56 \mathrm{pp}$.

Tramutoli V, 2007. Robust Satellite Techniques (RST) for Natural and environmental hazards monitoring and mitigation: theory and applications. Proc. IV Int. Workshop on the Analysis of Multitemporal Remote Sensing Images, Leuven, Belgium. IEEE, doi: 10.1109/multitemp.2007.4293057

Verron J, Le Provost C, 1985. A numerical study of a quasigeostrophic flow over isolated topography. J. Fluid Mech. 154:231-252.

Vignudelli S, Cipollini P, Reseghetti F, Fusco G, Gasparini GP, Manzella GMR, 2003. Comparison between XBT data and TOPEX/Poseidon satellite altimetry in the LigurianTyrrhenian area. Ann. Geophys. 21:123-135.

Villareal TA, Wilson C, 2014. A Comparison of the Pac-X TransPacific Wave Glider Data and Satellite Data (MODIS, Aquarius, TRMM and VIIRS). PLoSONE 9:e96968.

Willcox S, Meinig C, Sabine C, Lawrence-Slavas N, Richardson T, Hine R, Manley J, 2009. An autonomous mobile platform for underway surface carbon measurements in open-ocean and coastal waters, p. 1-8. Proc. Conf. MTS/IEEE Oceans 2009, Biloxi.

Wunsch C, 1997. The vertical partition of oceanic horizontal kinetic energy. J. Phys. Oceanogr. 27:1770-1794. 